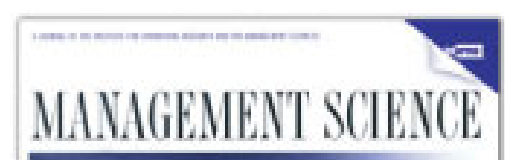

\title{
Management Science
}

Publication details, including instructions for authors and subscription information: http:// pubsonline.informs.org

\section{Adaptation to Information Technology: A Holistic Nomological Network from Implementation to J ob Outcomes}

Hillol Bala, Viswanath Venkatesh

\section{To cite this article:}

Hillol Bala, Viswanath Venkatesh (2016) Adaptation to Information Technology: A Holistic Nomological Network from Implementation to J ob Outcomes. Management Science 62(1):156-179. http:// dx. doi.org/ 10.1287/ mnsc. 2014.2111

\section{Full terms and conditions of use: http://pubsonline.informs.org/page/terms-and-conditions}

This article may be used only for the purposes of research, teaching, and/or private study. Commercial use or systematic downloading (by robots or other automatic processes) is prohibited without explicit Publisher approval, unless otherwise noted. For more information, contact permissions@informs.org.

The Publisher does not warrant or guarantee the article's accuracy, completeness, merchantability, fitness for a particular purpose, or non-infringement. Descriptions of, or references to, products or publications, or inclusion of an advertisement in this article, neither constitutes nor implies a guarantee, endorsement, or support of claims made of that product, publication, or service.

\section{Copyright @ 2016 , INFORMS}

Please scroll down for article-it is on subsequent pages

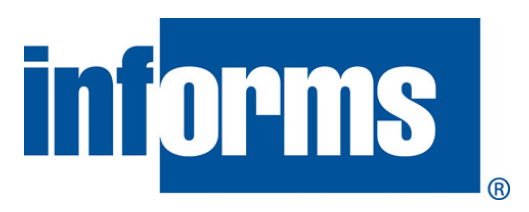

INFORMS is the largest professional society in the world for professionals in the fields of operations research, management science, and analytics.

For more information on INFORMS, its publications, membership, or meetings visit http:// www. informs. org 


\title{
Adaptation to Information Technology: A Holistic Nomological Network from Implementation to Job Outcomes
}

\author{
Hillol Bala \\ Kelley School of Business, Indiana University, Bloomington, Indiana 47405, hbala@indiana.edu \\ Viswanath Venkatesh \\ Walton College of Business, University of Arkansas, Fayetteville, Arkansas 72701, vvenkatesh@vvenkatesh.us
}

\begin{abstract}
Tnformation technology (IT) implementation is a major organizational change event that substantially disrupts 1 an employee's work environment. We develop a model of technology adaptation behaviors that employees perform to cope with a new IT that causes such disruptions. Our model posits technology adaptation behaviors as a key linking mechanism between IT implementation and employee job outcomes, thus offering a holistic nomological network of technology adaptation behaviors. Two field studies conducted over a period of six months, with four waves of data collection each, in two organizations $(N=211$ and $N=181)$ implementing two different ITs, supported the model. We found that employees performed four different technology adaptation behaviors-exploration-to-innovate, exploitation, exploration-to-revert, and avoidance-based on whether they appraised an IT as an opportunity or a threat and whether they had perceptions of control over an IT. Employees' experiential engagements (i.e., user participation and training effectiveness) and psychological engagements (i.e., user involvement and management support) during the implementation jointly determined their appraisal of an IT. Finally, we found that technology adaptation behaviors influenced changes in two key job outcomes, job performance and job satisfaction.
\end{abstract}

Keywords: technology adaptation; exploration; exploitation; avoidance; job performance; job satisfaction History: Received September 22, 2008; accepted March 3, 2013, by Sandra Slaughter, information systems.

Published online in Articles in Advance October 27, 2015.

\section{Introduction}

Notwithstanding the global economic slowdown in recent times, organizations around the world continue to implement information technologies (ITs) to gain operational and strategic benefits. Organizations are expected to spend close to $\$ 4.5$ trillion on ITs in 2017, with a spending growth rate of approximately $4 \%$ between 2014 and 2017 (Gartner Inc. 2013). Although there has been empirical evidence that IT implementations have a positive impact on firm performance (e.g., Mithas et al. 2012, Rai and Tang 2014), employee resistance remains a major challenge for organizations implementing ITs. Employees typically perceive major changes in their work environment and experience myriad expected and/or unexpected consequences following an IT implementation (Boudreau and Robey 2005, Morris and Venkatesh 2010, Venkatesh et al. 2010). Prior research has noted that when employees face such radical changes or disruptions, they tend to perform different adaptation behaviors to cope with the situation (e.g., Beaudry and Pinsonneault 2005, Fugate et al. 2008), with negative consequences ranging from resistance and underutilization to abandonment. Therefore, these key questions should be answered: how do employees adapt to a new IT that brings such changes and disruptions, what explains these adaptation behaviors, and what consequences do these behaviors have for employees?

We develop a holistic nomological network of technology adaptation behaviors that employees undertake to cope with an IT. Building on prior research, we define technology adaptation as the cognitive and behavioral efforts exerted by employees to manage perceived consequences associated with an IT implementation that occurs in their work environment (Beaudry and Pinsonneault 2005). Three distinct yet related streams of research have provided insights on employees' technology adaptation behaviors. The first stream, postadoptive IT use, offers insights on how and why individuals use an IT following their adoption decisions (e.g., Jasperson et al. 2005, Sun 2012, Sykes and Venkatesh 2015, Sykes et al. 2014). This research offers rich conceptualizations of IT use at different levels (e.g., individual, collective), examines predictors of IT use, highlights cognitive processes 
that users employ during IT use, and offers insights on recurrent interactions among the key elements of IT use (i.e., IT artifacts and work activities accomplished by using an IT artifact) and dynamic patterns of IT use. The second stream, user adaptation to IT, extends the postadoptive IT use literature by focusing on adaptation processes and strategies that employees undertake to cope with an IT (e.g., Beaudry and Pinsonneault 2005, Liang and Xue 2009). These adaptation strategies are holistic and are not necessarily limited to IT use (e.g., avoidance of an IT). This stream has thus provided insights on processes and phenomena that have not been the key focus in the postadoptive IT use literature, such as unintended or unfaithful use of an IT, improvisation, workarounds, and avoidance of an IT.

The third stream, closely related to the user adaptation to IT literature, focuses on recursive interactions between IT features, human agency, and institutional properties during IT implementations (e.g., Nan 2011, Purvis et al. 2001, Sharma and Yetton 2003). This stream provides insights on two distinct sets of processes of mutual adaptation when employees interact with a new IT. The first set of processes involves actions taken by employees to appropriate IT features and to adapt an IT to accomplish work. The second set of processes involves a set of metastructuration actions that include changes in institutional contexts, such as work processes, routines, organizational structure, control, coordination mechanisms, and reward structures. Together, these three streams suggest that employees embrace different adaptation strategies and perform various post-adoptive behaviors to cope with an IT. These streams also offer insights on adaptation processes and consequences related to how employees interact with an IT, and make changes to the structure of an IT and their work to cope with an IT.

Although prior research has provided rich insights on individuals' IT use, adaptation processes, and strategies, there has been limited understanding of specific adaptation behaviors that individuals undertake to cope with an IT, and the antecedents and consequences of these behaviors. To address this important gap, we develop and test a model of technology adaptation that incorporates four technology adaptation behaviors. We build on coping and adaptation theories from social psychology and information systems (IS) to identify the antecedents of these behaviors. We also build on the IT implementation literature to identify key implementation characteristics (i.e., employee engagements during an IT implementation) that, we suggest, will play a critical role in the adaptation process. Further, we longitudinally investigate the influence of these behaviors on changes in employee job outcomes-i.e., job performance and job satisfaction-between pre- and postimplementation of a new IT.

This research is expected to contribute to the IT implementation literature in at least three ways. First, we deepen our understanding of different postadoptive behaviors that employees exhibit following an IT implementation. In particular, we offer a set of adaptation behaviors that employees undertake to cope with an IT and provide a rich understanding of the nature of these behaviors. Second, our model links IT implementation to employee job outcomes and presents the adaptation process as a key linking mechanism. The model incorporates IT implementation characteristics and job outcomes from prior research and offers a comprehensive understanding of technology adaptation from antecedents to consequences. Thus, we extend recent studies that have linked IT implementation to employee job outcomes but do not focus on IT implementation characteristics and how employees adapt to a new IT (e.g., Ayyagari et al. 2011, Bala and Venkatesh 2013, Morris and Venkatesh 2010, Sykes et al. 2014, Venkatesh et al. 2010). Finally, we respond to calls for a rich conceptualization and operationalization of IT use (Burton-Jones and Straub 2006, Jasperson et al. 2005, Venkatesh et al. 2008). The adaptation behaviors proposed here augment and enrich our understanding of postadoptive IT use behaviors.

\section{Theory Development}

Our model (see Figure 1) leverages an influential theory of adaptation from social psychology-i.e., the transactional model of stress and coping (Lazarus and Folkman 1984) - and a model of user adaptation from IS-i.e., the coping model of user adaptation (CMUA; Beaudry and Pinsonneault 2005). These theories posit that individuals employ two processes when they encounter a stressful event and/or a change in their environment: cognitive appraisal and adaptation. The cognitive appraisal process involves an evaluation of whether an event is relevant to an individual's well-being and in what ways (Folkman et al. 1986). There are two aspects of cognitive appraisals: primary and secondary. A primary appraisal is one where an individual evaluates whether he or she has anything at stake in the event that has occurred-e.g., whether there is a potential for personal benefit or harm (Major et al. 1998). A secondary appraisal is one where an individual evaluates whether he or she has the resources and/or options to exert control over the situation so that he or she can overcome or prevent harm, or improve the prospects for benefit (Major et al. 1998). Coping theories do not explicitly theorize about the relative importance and sequence of these two appraisals. Instead, these theories emphasize the convergence or interaction of these appraisals 


\section{Figure 1 Research Model}

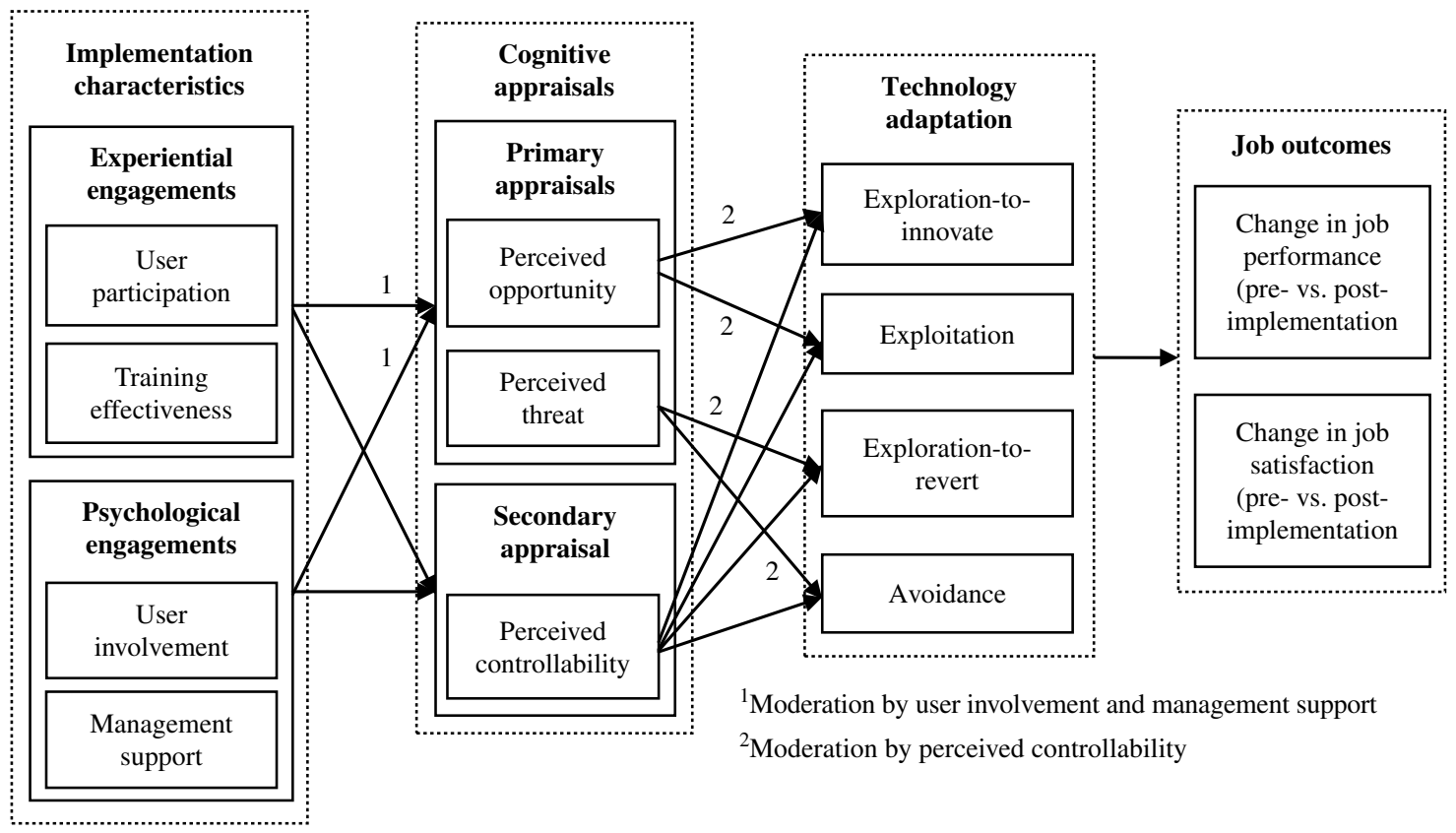

to explain individuals' adaptation behaviors (Carver et al. 1989).

These cognitive appraisals lead to the second process, adaptation, which represents cognitive and behavioral efforts exerted by an individual to manage a stressful event and/or a change in the environment (Lazarus and Folkman 1984). There are two major categories of adaptation strategies: problem-focused and emotion-focused (Carver et al. 1989, Folkman et al. 1986). Problem-focused adaptation strategies are used when an individual actively engages in activities directly aimed at solving the problem at hand and/or does something to alter the source of stress. Emotion-focused adaptation strategies are aimed at reducing or managing the emotional distress that is associated with or cued by the situation. Building on the transactional model of stress and coping, CMUA offers four adaptation strategies in the context of IT implementations: (a) benefits maximizing (e.g., taking full advantage of the opportunities offered by an IT to maximize personal benefits), (b) benefits satisficing (e.g., being satisfied with the limited benefits an IT offers), (c) disturbance handling (e.g., restoration of personal emotional stability and minimization of the perceived negative consequences associated with an IT), and (d) self-preservation (e.g., restoration of emotional stability, with little or no impact on individuals' performance at work using an IT). Coping theories offer numerous adaptational outcomes of coping that are specific to contexts that invoke adaptation processes. In organizational contexts, research has examined job outcomes, such as psychological well-being, organizational commitment, job satisfaction, and voluntary turnover as consequences of employee adaptation behaviors (e.g., Fugate et al. 2008).

2.1. Cognitive Appraisals of an IT Implementation Consistent with coping theories, our model posits that technology adaptation behaviors will operate as intervening mechanisms through which IT implementation characteristics and cognitive appraisals will influence employee job outcomes (see Figure 1). Building on CMUA, we conceptualize primary appraisals as perceived opportunity and perceived threat, and the secondary appraisal as perceived controllability (Beaudry and Pinsonneault 2005).

2.1.1. Primary Appraisals. Perceived opportunity is defined as the degree to which an employee believes that an IT implementation offers him or her a chance for success in the workplace. Although employees may perceive a chance for success in several aspects of their work following an IT implementation, such as personal growth, gain, reward, mastery, or job performance, they are likely to develop a holistic assessment of opportunity when they first encounter an IT in their work environment (Beaudry and Pinsonneault 2005). Prior research has offered various mechanisms through which employees may develop such an assessment. The IT adoption literature has suggested that employees are able to develop an assessment of whether using an IT will help them attain gains in job performance (Venkatesh et al. 2003). Perceived threat is defined as the degree to which an employee believes that an IT implementation harms his or her well-being, personal gain, or 
growth. Some employees may feel that an IT will degrade their performance and status in the organization because their roles in business processes may change after an implementation (Beaudry and Pinsonneault 2005, Lapointe and Rivard 2005). For example, an expert user of Microsoft Excel who uses it extensively to manage inventory may find a new IT that replaces Microsoft Excel lowers his or her status in the organization. Perceived threat has been suggested as a key antecedent of resistance to and avoidance of an IT (Lapointe and Rivard 2005, Liang and Xue 2009). We suggest that employees will develop an overall assessment of threat from an IT that will drive their perceptions of how an IT negatively affects different aspects of their work life.

Consistent with coping, organizational adaptation, and IT implementation literatures, our model posits that perceived opportunity and perceived threat are two theoretically distinct constructs. We argue that feeling that a new IT does not provide any opportunities does not necessarily indicate that the IT is threatening to the well-being of an employee. In the coping literature, opportunity and threat are theorized to be and tested as two distinct primary appraisals when individuals face changes and/or disruptions in their immediate environment (Beaudry and Pinsonneault 2005, Major et al. 1998). The organizational adaptation literature has likewise noted that opportunity and threat are two distinct executive cognitions that lead to different organizational adaptations (Chattopadhyay et al. 2001). In the IT implementation literature, opportunity (or benefit) and threat have been conceptualized and operationalized as two distinct technological frames that coexist in the mind of decision makers (Mishra and Agarwal 2010). Further, prior research has noted that two similar constructs, risk and reward/gain, are indeed distinct constructs because they are triggered by different theoretical processes (Yuan and Woodman 2010). For example, perception of risk is triggered by negative affective states, such as embarrassment, shame, and emotional instability, whereas reward/gain is triggered by self-enhancing motives activated by perceived opportunities for creating a favorable environment (Yuan and Woodman 2010). Because of these different triggers, individuals may perceive a situation to be highly risky and, at the same time, highly rewarding. In sum, consistent with the IS literature (Beaudry and Pinsonneault 2005, Mishra and Agarwal 2010) and coping theories from the social psychology literature (e.g., Major et al. 1998), we suggest that perceived opportunity and perceived threat are two distinct assessments of primary appraisals that will be activated by different triggers, and employees will develop these two salient technological frames when they encounter an IT in their work environment.
2.1.2. Secondary Appraisal. Perceived controllability is defined as the degree to which an individual feels that he or she has the ability and resources to deal with a new IT. Although developed as part of different theoretical paradigms, perceived controllability, perceived behavioral control, self-efficacy, and facilitating conditions have significant conceptual similarities (Venkatesh et al. 2003). Coping theories suggest that individuals will form an overall perception of control based on their current level of competence to deal with a demanding situation and their ability to leverage external resources that help them handle the situation. Our model theorizes perceived controllability as a situational control that is needed to invoke situation-specific coping strategies (Beaudry and Pinsonneault 2005, Carver et al. 1989, Major et al. 1998). The evaluation of control is particularly critical because employees will have varying degrees of perceptions of control following an IT implementation. In addition to personal ability/resources to effectively use an IT, individuals will consider the availability of external resources when forming perceptions of control.

\subsection{Technology Adaptation}

Adaptation has been studied extensively in social psychology and organizational behavior literatures (e.g., Chan 2000). Chan (2000) described situations in which an individual needs to be adaptive. The coping literature has suggested that adaptation is contextual because an individual needs different adaptation efforts to cope with different situations (Folkman et al. 1986). Consistent with this view and CMUA, we postulate technology adaptation as a contextual construct pertinent to IT implementation contexts. We reviewed research on postadoptive IT use and user adaptation to IT to identify and conceptualize the four adaptation behaviors incorporated in our model. We also used the comments from employees of a Fortune 500 manufacturing company who participated in focus group sessions that we conducted as part of this research to enrich our conceptualization of these behaviors. During these sessions, a moderator asked a standard set of questions to elicit participants' general reactions to a newly implemented IT. The participants were allowed to freely express their reactions, discuss among themselves, and provide examples in support of their points when possible. All the comments were recorded, transcribed, and content analyzed (Stewart et al. 2007). These focus groups validated the use of these four behaviors by the employees. We discuss the illustrations from the focus groups for hypotheses related to the adaptation behaviors to further strengthen justifications for our hypotheses. The four major themes that emerged from the literature review and the focus group sessions 
are exploration-to-innovate, exploitation, explorationto-revert, and avoidance.

We draw on the organizational adaptation and learning literature, as well as coping theories, to conceptualize these behaviors. The organizational adaptation and learning literature conceptualizes exploration as the search for novel or innovative ways of doing something and associates it with different phenomena, such as search, variation, risk taking, experimentation, play, flexibility, discovery, and innovation (e.g., Gupta et al. 2006). In contrast, exploitation refers to the routine execution of knowledge associated with various phenomena, such as refinement, choice, production, efficiency, selection, implementation, and execution (Gupta et al. 2006). Although learning, improvement, and acquisition of new and contextual knowledge is central to both exploration and exploitation, it is the type or amount of learning that differentiates these two adaptation behaviors (Gupta et al. 2006). In the context of IT implementations, prior research has noted that employees' learning, improvement, and acquisition of new knowledge typically take place along two contextual aspects of IT use: technology and work processes (e.g., Nan 2011). We suggest that technology adaptation behaviors in our model will capture learning, improvement, and acquisition of contextual knowledge pertinent to these two aspects of IT use.

Coping theories-i.e., the transactional model of stress and coping and CMUA-also provide the theoretical foundations for the adaptation behaviors in our model. These behaviors are consistent with the theoretical mechanisms and processes proposed in CMUA regarding interactions of cognitive appraisals leading to the different adaptation strategies that employees undertake. Moreover, consistent with CMUA, adaptation behaviors in our model have components from both problem-focused and emotion-focused adaptations. Further, consistent with CMUA, our model offers a broad view of adaptation behaviors that incorporates adaptations of IT (e.g., changing features of an IT), work (e.g., modifying procedures and routines), and self (e.g., adjusting personal habits). Given the complexity of an IT, it is possible that employees undertake multiple adaptation behaviors concurrently (Beaudry and Pinsonneault 2005). However, the salience of these behaviors to employees will depend on the magnitude and nature of interactions of primary and secondary appraisals (Beaudry and Pinsonneault 2005, Major et al. 1998).

2.2.1. Predicting Exploration-to-Innovate. Exploration-to-innovate is defined as the degree to which an employee tries to find, extend, and/or change features of an IT to accomplish his or her tasks in novel ways. Prior research has suggested that some employees will exert considerable effort to explore an IT to discover new features and ways of accomplishing their work processes in creative, novel, and improvised ways (Beaudry and Pinsonneault 2005, Boudreau and Robey 2005, Robey et al. 2002). An interesting example from a focus group participant was how she discovered a feature in a newly implemented product data management system to attach multiple product codes to a single project so that the project could move forward without any delay. Although this feature of the new IT helped this employee perform her tasks in an innovative way, it was not discussed or mentioned during the training provided by the vendor of the new IT. Explorationto-innovate is conceptually similar to feature extension, feature exploration, and infusion or emergent use of IT (Jasperson et al. 2005, Thatcher et al. 2011). Further, employees engaged in exploration-toinnovate behaviors cognitively undertake a benefitsmaximizing strategy to take full advantage of an IT. Thus, exploration-to-innovate is a problem-focused adaptation because employees will proactively be involved in feature discovery, extension, and improvisation for their personal gains (e.g., improved job performance) and growth.

We posit that perceived opportunity and perceived controllability will have both direct and moderating effects on exploration-to-innovate. Given that the theoretical triggers of perceived threat are primarily related to the potential harmful effects of an IT (Lapointe and Rivard 2005, Liang and Xue 2009), we do not have a theoretical rationale for expecting that perceived threat will be an antecedent of explorationto-innovate. In other words, in the presence of perceived opportunity, perceived threat is likely to recede into the background as employees contemplate the positive consequences of finding innovative uses of a new IT. When employees appraise an IT as an opportunity to succeed in their workplace (e.g., mastery, professional growth, improved job performance, formal recognition), they are more likely to try to use the IT to maximize this opportunity. Employees will exert effort to find and use different features of the IT to perform their tasks and materialize these opportunities (Beaudry and Pinsonneault 2005). We further suggest that if employees feel that they have the necessary knowledge and resources to use an IT effectively (i.e., perceived controllability), they are more likely to apply this knowledge and resources to use the IT to gain as much as possible from the IT. An employee will only be able to perform the exploration-to-innovate behaviors (e.g., discover, learn, acquire, and apply features of an IT) if he or she has the relevant knowledge and resources to do so. Hence, we suggest that, if an employee appraises an IT implementation as an opportunity and, at the same time, feels that he or she has the ability and resources 
to find and use different features of the IT (i.e., perceived controllability), he or she will be even more motivated (than he or she is in the absence of control) to take an active or problem-solving coping strategy to explore the IT to find ways to maximize benefits (Beaudry and Pinsonneault 2005). The feeling of control over the IT will enhance the desire to leverage the opportunities that the IT offers. Therefore, under the condition of high perceived controllability, the effect of perceived opportunity on exploration-to-innovate will be even stronger, because employees will attempt to find or discover system features to maximize their benefits and improve their well-being.

Hypothesis 1 (H1). (a) Perceived opportunity and (b) perceived controllability will positively influence exploration-to-innovate, and (c) perceived controllability will moderate the relationship between perceived opportunity and exploration-to-innovate, such that the relationship will be stronger when perceived controllability is high.

2.2.2. Predicting Exploitation. Exploitation is defined as the degree to which an employee uses a recommended set of features of an IT to perform his or her portfolio of tasks. Burton-Jones and Straub (2006) discussed exploitive system use in developing a rich conceptualization of IT use. Exploitation is conceptually similar to feature adoption and employment behaviors (Jasperson et al. 2005), deep structure use (DeSanctis and Poole 1994), and routine use of an IT (Thatcher et al. 2011). More specifically, exploitation entails employees' adoption of a set of IT features that they learn from training sessions and/or from others (e.g., peers, supervisors, help desk) and use of these features on a regular basis to accomplish their work processes. They become experts in using these features and are able to leverage them to accomplish their tasks efficiently. Several participants in our focus group sessions mentioned that they typically used a set of known features of the IT on a regular basis to accomplish their tasks. Although they mastered these features and felt that these features helped them perform their tasks efficiently, they did not know much about the other features of the IT. Drawing on CMUA, we suggest that employees cognitively employ a benefits-satisficing strategy when they engage in exploitation behaviors. Given that the benefits-satisficing strategy has both problem- and emotion-focused aspects (Beaudry and Pinsonneault 2005), employees engaged in exploitation are likely to invoke elements of both of these aspects as they exploit an IT. For example, some employees will be willing to exploit the features of an IT to perform their tasks in a satisfactory manner (i.e., problemfocused adaptation). However, they may not be able to gain additional benefits because of their inability to go beyond the features that they learn to exploit.
Hence, they continue to exploit the IT to reduce the emotional dissonance caused by their inability to use other features of an IT to gain more from the IT (i.e., emotion-focused adaptation).

Following an IT implementation, a set of procedures or steps is typically suggested or prescribed to help employees perform their work processes using the new IT. These steps may vary across organizations and ITs. When employees feel that an IT is beneficial to them, they are more likely to find ways to leverage the suggested features of the IT to achieve these benefits. Hence, perceived opportunity will be the salient primary appraisal for exploitation. Perceived threat will not be salient in the presence of perceived opportunity because employees are likely to exploit the features of an IT when they are aware of the positive consequences of using these features (cf. Beaudry and Pinsonneault 2005). We suggest that perceived controllability will have a negative influence on exploitation. Given that employees performing exploitation behaviors are likely to use a fixed set of features on a regular basis, they do not need a high degree of control over the new IT (Beaudry and Pinsonneault 2005). In fact, a high degree of control may diminish their motivation to continue to engage in exploitation behaviors. We further suggest that, under the condition of low perceived controllability, employees will place more importance on perceived opportunity when they engage in exploitation. If employees perceive that they do not have the ability and resources to use an IT to the fullest extent (i.e., low perceived controllability), they are more likely to resort to using a known set of features to satisfy their needs. Some participants in our focus group sessions mentioned that they did not fully understand the purpose of some features of the new IT. In fact, they thought that the new IT was significantly more complex than the previous IT. However, they felt that they were still able to gain benefits from the new IT because they knew the "right" features that they used routinely to perform their tasks.

Hypothesis 2 (H2). (a) Perceived opportunity will positively influence exploitation, (b) perceived controllability will negatively influence exploitation, and (c) perceived controllability will moderate the relationship between perceived opportunity and exploitation, such that the relationship will be stronger when perceived controllability is low.

2.2.3. Predicting Exploration-to-Revert. Exploration-to-revert occurs when an employee tries to find, extend, and/or change features of an IT to fit with his or her preimplementation work processes and/or habits. Prior research has suggested that employees often engage in workarounds when using an IT (Boudreau and Robey 2005, Volkoff et al. 2007). Robey et al. (2002) found that, instead of learning the new 
technology and work processes, some users tried to return to what they had done in the past, including workarounds. They also found that some users pulled data off the new system for analysis using their old desktop software. Exploration-to-revert behaviors are not consistent with the spirit of an IT (i.e., the general intent with regard to values and goals underlying a given set of features of an IT, which is the official line that determines how employees should act when using an IT; DeSanctis and Poole 1994) and are typically not the prescribed manner to interact with an IT. Exploration-to-revert behaviors may create problems in organizations because if an employee does not use an IT properly, he or she may hinder the successful execution of an entire business process. We suggest that when employees engage in exploration-to-revert behavior, they cognitively undertake a disturbance-handling strategy suggested in CMUA to restore emotional stability and minimize the perceived negative consequences of an IT. Hence, exploration-to-revert has both problem- and emotion-focused aspects. The problem-focused aspect is manifested through employees' efforts to manage unfavorable situations by searching features of an IT to perform tasks in old ways. The emotion-focused aspect is revealed through employees' efforts to restore emotional stability by trying to return to their previous routines (Beaudry and Pinsonneault 2005).

We argue that if an employee perceives that an IT may harm his or her well-being (e.g., increasing anxiety and stress), prevent personal gain or growth (e.g., declining performance), or degrade his or her social status in the organization (i.e., perceived threat), he or she is more likely to try to find ways to minimize these potential harms. He or she will be less motivated to leverage the features of an IT to perform his or her work processes because he or she may fear that the consequences will not be beneficial. We suggest that, in such a situation, employees will engage in exploration-to-revert behaviors. We further suggest that the appraisal of perceived opportunity will not be as salient as perceived threat in such a situation because the perception of potential positive consequences of an IT will recede to the background as employees attempt to find ways to minimize the potential harmful effects of the new IT. Perceived controllability will have a positive influence on exploration-to-revert because if employees want to explore the features of a new IT to perform their tasks in old ways, they need to have a high degree of knowledge and resources related to the new IT (Beaudry and Pinsonneault 2005). Given that exploration-to-revert behaviors are not encouraged and the formal training provided by organizations does not usually cover features or steps that encourage such behaviors, employees who want to perform these behaviors need to develop an ability to perform such behaviors. We further argue that employees will exhibit the strongest exploration-to-revert behavior if they perceive high threat and high controllability at the same time. In particular, in the presence of high perceived controllability, employees will be highly motivated to explore system features to minimize the perceived negative consequences (Beaudry and Pinsonneault 2005). They will leverage their ability and resources to find features to fit with their old ways of doing things to minimize the threatening aspects of the IT. Several of our focus group participants felt that using the new IT would, in fact, degrade their performance. They were worried that they might lose their status in their business units as top performers and that their coworkers might no longer consult them for work-related needs. These employees, however, mentioned that they explored the new IT to see whether there were ways to perform their tasks using the old ways. For instance, a participant mentioned that she was able to find data from the new IT, write it down on a piece of paper, and use the data to manually search other ITs to find the status of a new product development project.

Hypothesis 3 (H3). (a) Perceived threat and (b) perceived controllability will positively influence explorationto-revert, and (c) perceived controllability will moderate the relationship between perceived threat and explorationto-revert, such that the relationship will be stronger when perceived controllability is high.

2.2.4. Predicting Avoidance. Avoidance is defined as the degree to which an employee tries not to use an IT when accomplishing his or her tasks. Klein et al. (2001) indicated that some users will try to avoid an innovation altogether. Beaudry and Pinsonneault (2005) found that some employees did not use an IT at all because they thought that they would be able to accomplish their tasks efficiently without using the IT. Bendoly and Cotteleer (2008) found that managers and employees had strong intentions to circumvent (i.e., avoid) an IT in the presence of perceived tasktechnology misfit. In keeping with coping theories, we conceptualize avoidance as an emotion-focused adaptation because employees attempt to psychologically remove themselves from the demands of the stressor (i.e., an IT) without doing anything to actually change the reality of the situation (Folkman et al. 1986). Building on CMUA, we suggest that employees undertake a self-preservation strategy when they engage in avoidance to restore emotional stability and reduce tensions related to using an IT. Unlike exploration-to-revert behaviors that are characterized by an employee's exploration of an IT to find support for his or her old work processes and/or habits, 
avoidance reflects an employee's total abandonment of an IT.

Consistent with coping theories and prior IS research, we suggest that if employees perceive an IT implementation as a threat (e.g., having perceived harmful consequences, such as anxiety and declining performance), one of their immediate behavioral responses will be to try to avoid the IT to minimize these negative consequences and restore emotional stability (Liang and Xue 2009). Several of our focus group participants complained about how the new IT increased their workloads by requiring them to constantly update the progress of their assigned tasks. These employees repeatedly mentioned that the previous IT and work processes were efficient ("... it was working well...not sure if we really needed this new software"). They also commented that they would prefer not to use the new IT to perform their tasks. This is consistent with prior research that found that, if an IT threatens the status quo, employees are more likely to avoid it, if possible (Beaudry and Pinsonneault 2005, Boudreau and Robey 2005, Robey et al. 2002). Perceived controllability is expected to have a negative influence on avoidance because perceptions of control are critical for behavioral performance (Ajzen 1991) - if employees perceive that they do not have the ability or resources to use an IT effectively, they are likely to try to avoid the IT. We further suggest that employees will exhibit the strongest avoidance behavior in the presence of high threat and low controllability. In particular, when employees feel that they do not have the ability and resources to cope with an IT (i.e., low perceived controllability), the harmful consequences of the IT will be even more salient to them because of their inability to overcome or find ways to minimize these consequences by leveraging the IT (Beaudry and Pinsonneault 2005). Consequently, employees may feel that the best course of action is to avoid using the IT altogether to prevent these harmful consequences.

Hypothesis 4 (H4). (a) Perceived threat will have a positive influence on avoidance, (b) perceived controllability will have a negative influence on avoidance, and (c) perceived controllability will moderate the relationship between perceived threat and avoidance, such that the relationship will be stronger when perceived controllability is low.

\subsection{IT Implementation Characteristics and Cognitive Appraisals}

Coping theories suggest that, when understanding employee adaptation behaviors after an organizational change, it is important to take into account the characteristics of the change event (Beaudry and Pinsonneault 2005, Lazarus and Folkman 1984). Further, these theories suggest that individuals try to leverage context-specific resources when they appraise a stressful event and/or a change in their environment. Consistent with coping theories, we include four widely used IT implementation characteristicsuser participation (Barki and Hartwick 1994), training effectiveness (Sharma and Yetton 2007), user involvement (Barki and Hartwick 1994), and management support (Sharma and Yetton 2003) - in our model as situational characteristics and coping resources that will help employees appraise an IT implementation. Recent studies have offered theoretical and empirical insights on the influence of these characteristics on user cognitions, behaviors, and outcomes (e.g., Sabherwal et al. 2006, Sharma and Yetton 2007, Sykes 2015, Venkatesh et al. 2011).

We organize these characteristics into two categories based on whether they refer to employees' behavioral or psychological engagements with an IT implementation: (a) experiential engagements and (b) psychological engagements. Experiential engagements represent those characteristics that capture employees' behavioral undertaking during an IT implementation through visible actions, whereas psychological engagements are those characteristics that capture psychological association of employees with an IT implementation (Barki and Hartwick 1994). Our model posits that the experiential engagements will have a direct effect on cognitive appraisals because these factors will help employees make an informed decision about whether an IT is an opportunity or a threat (i.e., primary appraisals) and whether they have the ability and resources to use it effectively (i.e., secondary appraisals). These factors will help employees gain both declarative and procedural knowledge of an IT that in turn helps them shape their perceptions of opportunity, threat, and controllability. In contrast, we suggest that the psychological engagements will have both direct and moderating effects on cognitive appraisals because these factors will create a psychological environment during an IT implementation that helps employees determine their levels of experiential engagements to accurately appraise an IT. Our model does not posit moderating effects of psychological engagements on perceived controllability because we expect that perceptions of control will primarily be shaped by the experiential engagements that represent employees' interactions with an IT, and the presence (or absence) of psychological engagements will not alter how these interactions will shape employees' perceptions of control over an IT.

2.3.1. Experiential Engagements and Cognitive Appraisals. User participation, the first experiential engagement factor, refers to the assignments, activities, and behaviors that users or their representatives perform during an IT implementation (Barki 
and Hartwick 1994). Training effectiveness, the second experiential engagement factor, is defined as the degree to which an individual believes that the training provided during the IT implementation is adequate to work with the IT (Aiman-Smith and Green 2002). We suggest that these two experiential engagements will influence all three cognitive appraisals. Participation (e.g., system evaluation and customization, prototype testing, and involvement in business process change initiatives) and training will help employees develop an accurate perception of different features of an IT (Barki and Hartwick 1994, Sharma and Yetton 2007). They are more likely to form perceptions of the opportunity that the IT offers in terms of personal gains and growth in the organization (Sabherwal et al. 2006). Along the same line of reasoning, we suggest that, if employees or their representative(s) actively participate in an IT implementation and/or receive effective training, it is possible that they will have information regarding the threatening aspects of an IT, if any. Such participation will allow employees to exert influence on decisions related to the customization of an IT during implementation. Employees may have the opportunity to use the IT for testing purposes and/or during training. As employees learn more about the IT and develop a greater understanding of its features, they will be less threatened by it. Moreover, during training, coworkers' knowledge of the IT, shared as transactive memory, will help employees learn potential benefits and overcome threatening aspects of an IT (Sharma and Yetton 2007). Effective training will also help employees develop a sense of mastery over an IT's features. Finally, if employees have better knowledge of the features of the new IT, as well as a greater understanding of how it fits into their work processes and how they can use it to accomplish their tasks, they are more likely to believe that they have the ability and resources to understand and work with the new IT (i.e., have greater control over the new IT).

Hypothesis 5 (H5). User participation will (a) positively influence perceived opportunity, (b) negatively influence perceived threat, and (c) positively influence perceived controllability.

Нypothesis 6 (H6). Training effectiveness will (a) positively influence perceived opportunity, (b) negatively influence perceived threat, and (c) positively influence perceived controllability.

2.3.2. User Involvement and Cognitive Appraisals. User involvement, the first psychological engagement factor, refers to a subjective psychological state reflecting the importance and personal relevance of a new IT to an employee (Barki and Hartwick 1994). When employees perceive that an IT is important to them and that the IT has a high degree of personal relevance to them, they are more likely to be interested in learning and mastering its features. They are likely to develop a sense of ownership of the new IT. A good understanding of the features will help them realize the potential benefits of the IT in various aspects of their job. They will feel that the new IT will bring opportunities for well-being and personal growth. We further argue that if employees perceive that an IT is important and relevant to them, they are more likely to be less threatened by the IT. Given that they are likely to learn and master the new IT, they will be able to minimize its threatening aspects (e.g., anxiety associated with IT use). Also, highly involved employees will consider the IT to be an important resource that helps them succeed in the organization (Barki and Hartwick 1994). Consequently, they will not consider the IT to be threatening to their well-being. Further, employees with a high degree of involvement may attempt to increase their abilities to use an IT and proactively seek resources that can potentially help them use it effectively. Hence, employees will develop a perception of control over an IT, although such perceptions may not be an accurate reflection of employees' abilities to use it effectively.

Нypothesis 7 (H7). User involvement will (a) positively influence perceived opportunity, (b) negatively influence perceived threat, and (c) positively influence perceived controllability.

2.3.3. Management Support and Cognitive Appraisals. Management support, the second psychological engagement factor, is defined as the degree to which an employee believes that the management in the organization has committed to the successful implementation of an IT (Sharma and Yetton 2003). If employees feel that the management actually believes that the IT will be beneficial to the employees and communicates such beliefs, it is more likely that employees will see opportunities in the IT in terms of gaining status in the organization or performing their tasks effectively using the IT. Further, if the management supports the new IT, employees may see an opportunity for using the new IT and being rewarded by the management for that use. Employees may develop a sense of psychological safety and structural assurance that they will not lose their job or status in the organization because of their use of the IT (Edmondson 1999). Further, the management might provide explicit assurance in areas that are potential sources of IT-related threats (e.g., tolerance for performance loss during an IT implementation). Also, perceptions of management support can make employees feel that they are allowed to freely use different features of a new IT to accomplish their tasks. Such emotional and behavioral support will 
help employees develop a sense of control over the new IT and assurance that there will be resources available to help them learn and use the IT. Consequently, they will develop a heightened sense of control over the IT.

НYPOTHEsis 8 (H8). Management support will (a) positively influence perceived opportunity, (b) negatively influence perceived threat, and (c) positively influence perceived controllability.

2.3.4. Moderating Role of User Involvement. Although employees with a high degree of user participation will develop a heightened sense of perceived opportunity, it is possible that this effect will be even stronger for those employees with low user involvement. Under the condition of low user involvement, it is more likely that employees will have no inherent motivation to learn about the potential positive consequences of an IT. However, if these employees are asked to participate in an IT implementation, they will be able to learn about the IT's features through participation. User participation will be a driving force for these employees to discover the benefits of the new IT. We note that employees with high user involvement will also benefit from participating in the implementation process. They will be highly motivated to learn about the new IT through their participation. However, we argue that employees with low user involvement will gain the most from the participation process because they are likely to engage in the participation process without much prior knowledge of the new IT, because they did not consider it to be relevant and important to them (i.e., low user involvement). Consequently, they will gain more through participation (i.e., the difference between their pre- and postparticipation knowledge of an IT will be higher) than employees with high user involvement who are likely to have some prior knowledge of the IT before they are formally engaged in user participation. The former is likely to identify avenues of opportunity through participation that were unknown to them before the participation. In contrast, it is possible that employees with high user involvement are aware of potential opportunities even before they participate in the implementation process. Therefore, under the condition of low user involvement, user participation will have a stronger positive effect on perceived opportunity. Along the same lines, the negative relationship between user participation and perceived threat will be stronger (i.e., participation will mitigate the potential threats related to an IT) for employees with low user involvement.

We posit that user involvement will positively moderate the relationship between training effectiveness and perceived opportunity. If an IT is perceived to be important and relevant by an employee, he or she is likely to feel an urge to learn, explore, and master it if there is an opportunity to do so (e.g., training). Overall, the employee will attempt to increase his or her ability to use the IT and proactively seek resources that can potentially help him or her use the IT effectively. Developing an understanding of different features of an IT and how they relate to job requirements will create a perception of opportunity. Therefore, in the presence of high user involvement, employees will place more importance on training so that they can learn various ways that the IT can benefit them. Similarly, when employees believe that an IT is important and relevant to them, they are likely to leverage whatever they learned from training to minimize or alleviate the threatening aspects of the IT, if any. For example, an employee may believe that a newly implemented IT is complex and may lower his or her job performance (i.e., perceived threat). However, if the employee feels that the system is important and relevant for work, he or she is likely to take advantage of the training to find ways to minimize the threatening aspects of the system (i.e., complexity). Hence, the negative effect of training effectiveness on perceived threat will be strengthened in the presence of high user involvement.

Hypothesis 9 (H9). User involvement will moderate the relationship between (a) user participation and perceived opportunity, (b) user participation and perceived threat, (c) training effectiveness and perceived opportunity, and (d) training effectiveness and perceived threat, such that the relationship is stronger when user involvement is low (for (a) and (b)) and high (for (c) and (d)).

2.3.5. Moderating Role of Management Support. We postulate that management support will positively moderate the relationships between user participation and perceived opportunity (threat) and between training effectiveness and perceived opportunity (threat). We argue that management support operating through the theoretical mechanisms of psychological safety and structural assurance will motivate employees to engage actively in an IT implementation that helps them develop accurate perceptions of the benefits of the IT. At the same time, such engagement will reduce ambiguity and uncertainty in the environment during the implementation (Edmondson 1999). Given that user participation and training are two formal mechanisms for experiential engagements with the IT implementation, employees will leverage these mechanisms to engender favorable perceptions of the IT and overcome the threatening aspects of the IT. When management support is high, employees are likely to be motivated to reflect on their participation and training experiences to (dis)confirm the potential consequences of 
the IT (i.e., opportunity or threat). Edmondson (1999) noted that perceptions of psychological safety create an environment of learning. Therefore, employees will be motivated to learn about the potential consequences of the IT through participation and training. Further, when managers are committed to an IT, they are more likely to invest in and monitor the quality of the implementation process. Consequently, employees will be actively engaged in participation and training activities to satisfy and impress their supervisors and to (dis)confirm their perceptions of the IT's consequences.

Hypothesis 10 (H10). Management support will moderate the relationship between (a) user participation and perceived opportunity, (b) user participation and perceived threat, (c) training effectiveness and perceived opportunity, and (d) training effectiveness and perceived threat, such that the relationship is stronger when management support is high.

\subsection{Technology Adaptation and Job Outcomes}

We incorporate job performance and job satisfaction, two of the most widely used job outcomes, in our model, because they provide a holistic view of employees' effectiveness in their jobs and affective evaluation of their jobs, respectively (Harrison et al. 2006). We posit that technology adaptation behaviors will influence changes in these outcomes between preand postimplementation phases.

2.4.1. Exploration-to-Innovate and Job Outcomes. We argue that exploration-to-innovate will have a positive influence on employees' job performance and job satisfaction following an IT implementation. Given that exploration-to-innovate is a problem-focused active adaptation behavior, employees will explore the features of the IT to find effective and efficient ways to fulfill their task requirements (Carver et al. 1989). CMUA posits that adaptation efforts that are "oriented toward reaping the benefits... are likely to result in performance improvements such as reducing errors, doing the work faster..." (Beaudry and Pinsonneault 2005, pp. 500-501). Boudreau and Robey (2005) found that employees reinvented different features of an enterprise resource planning (ERP) system through improvised learning. They argued that reinvention helped employees overcome system constraints and perform tweaks to complete their tasks effectively and efficiently. We earlier noted that a participant in one of our focus group sessions described how she was able to discover a new feature of the IT to handle multiple products in a single project and expedite project activities. She also noted that because of her ability to use this feature, she was able to work on multiple projects concurrently, and her performance improvement was recognized by her supervisor and coworkers. Therefore, we suggest that employees engaging in exploration-to-innovate will find features of the IT for new applications and innovative use that will ultimately increase (compared to preimplementation levels) their job performance in the workplace.

We further argue that exploration-to-innovate will help employees fulfill the job-related needs that determine their affective reactions toward the job and work environments, i.e., job satisfaction (Harrison et al. 2006). If employees explore an IT to find novel ways to accomplish their tasks, they will feel empowered and believe that their jobs are enriched due to the IT. Also, exploration-to-innovate can potentially transform their mundane work processes into interesting sets of activities, thus enriching and transforming the nature of work performed by them (Ang and Slaughter 2001). Job enrichment and transformation are important sources of job satisfaction (Harrison et al. 2006). During our focus group sessions, we noticed that employees who claimed to be proactively engaged in innovative uses of the new IT repeatedly expressed how much they "love" their jobs and the new IT. For example, an employee who discovered a feature to import the data from the spreadsheets that he personally developed to the new IT described how "happy" he was with his job and the new IT. Overall, exploration-to-innovate will lead to an increase in job satisfaction by enriching and transforming the nature of work.

НүротнеSIS 11 (H11). Exploration-to-innovate will positively influence an increase in (a) job performance and (b) job satisfaction following an IT implementation.

2.4.2. Exploitation and Job Outcomes. We suggest that exploitation will have a positive influence on job performance because when employees exploit an IT (e.g., repeatedly use a recommended set of features to perform their tasks), they become experts in these features and can leverage these features to enhance their effectiveness and efficiency in performing their job duties. As a result, their job performance will improve (compared to preimplementation levels). Participants in our focus groups mentioned that the new IT led to efficiency gains in product development projects. They mentioned a few core features of the IT that helped them track their assigned tasks in the overall workflow, the status of their coworkers' tasks, and overall project progress. They commented that they were more efficient and effective in their tasks (than they were preimplementation) because of these features of the new IT.

We suggest that exploitation will have a positive influence on job satisfaction. Beaudry and Pinsonneault (2005, p. 501) noted that employees can 
"relax and enjoy life" when they have to carry out minimal adaptation to satisfy their needs. Compared to exploration behaviors, exploitation requires minimal adaptation because employees leverage a set of features that they learn from training or from others to perform their day-to-day tasks. Employees may develop a sense of job enrichment and transformation as they leverage a few core features and carry out their tasks following the spirit of the new IT. Several focus group participants mentioned that they were overall happy with their jobs because the new IT made their work much more enjoyable. Some participants mentioned that there was a sense of relaxation and fairness in the workplace because employees were able to see and track the status of different tasks assigned to them and their coworkers on a regular basis using the tracking feature of the new IT. In sum, exploitation will possibly contribute to job satisfaction because employees will be able to relax and enjoy their work and feel that the IT will help fulfill their job-related needs.

Нүротнеsis 12 (H12). Exploitation will positively influence an increase in (a) job performance and (b) job satisfaction following an IT implementation.

2.4.3. Exploration-to-Revert and Job Outcomes. In contrast to exploration-to-innovate, we suggest that exploration-to-revert will have a negative influence on job performance and job satisfaction. Following an IT implementation, managers are likely to assess employees' job performance based on how well the employees are able to perform their tasks using the new IT. Given that an IT implementation usually leads to changes in employees' work processes (Volkoff et al. 2007), we suggest that when employees explore an IT to find ways to fit with their old ways of executing work processes (i.e., exploration-to-revert), they will be less effective and efficient in fulfilling the requirements of the new work processes. For example, if an employee copies data from an ERP system, uses Microsoft Excel to analyze the data instead of using the built-in analytical features in the ERP system, and then inserts the results back into the ERP system, it is possible that these steps will make his or her work processes less efficient and may even introduce errors. Consequently, his or her job performance will decrease.

We suggest that employees may develop negative reactions toward their jobs and work environment as they engage in exploration-to-revert behaviors. Given that employees will attempt to find ways to perform their tasks using the old ways, they may not feel that their jobs are enriched or transformed by the new IT. In fact, they may feel that they are much worse off because they have to use an IT that does not readily offer features that will support their old ways of performing their jobs. As employees spend time exploring the IT in order to perform their tasks using their old (i.e., preferred) ways, they may not get support from their supervisors and coworkers who are more willing to perform their tasks by using the new IT. Consequently, employees may become frustrated with their jobs and work environment. In fact, prior research has noted that when employees feel threatened by a new IT and try to find ways to go back to their old habits and work processes, they develop negative affective reactions toward their jobs in general (e.g., Boudreau and Robey 2005). Some of our focus group participants mentioned that although they were able to retrieve data from the new IT and analyze the data using other ITs (that they used in the past), they were not able to find ways to reconcile the data between the new and old ITs. They were increasingly frustrated with their jobs because their supervisors and coworkers were not able to get an accurate update of what these employees were doing.

Hypothesis 13 (H13). Exploration-to-revert will positively influence a decrease in (a) job performance and (b) job satisfaction following an IT implementation.

2.4.4. Avoidance and Job Outcomes. If employees try to avoid an IT when performing their tasks, it is more likely that their job performance will decline. Employees are typically assigned certain roles in the business processes enabled by the IT (Volkoff et al. 2007). When employees avoid the IT, they will not be able to meet the requirements of the roles assigned to them (Lapointe and Rivard 2005). If an employee avoids the IT altogether to perform a task (that is supported by the IT), coworkers and supervisors may not able to figure out how he or she performed the task because there might not be any record (and/or associated data) related to the task. Further, following an IT implementation, organizations may change performance evaluation criteria and expect employees to be more effective and efficient in performing their tasks by leveraging the IT (Xue et al. 2011). In such a situation, avoidance will prevent employees from being more effective and efficient in performing their tasks. Thus, avoidance will lead to a decrease in job performance against the new standards. Although focus group participants did not explicitly discuss avoidance behaviors, some participants mentioned that they continued to use Microsoft Excel for much of their work although its use was discouraged after the implementation of the new IT. They admitted that the use of Microsoft Excel was inefficient and time consuming because they also had to enter the same data in the new IT to accomplish their assigned tasks in the product development projects.

With respect to job satisfaction, we argue that if employees avoid an IT, they will not be able to leverage its features to enrich and transform their jobs. 
They will not find the IT to be helpful in fulfilling their job needs. Further, employees may experience deteriorating relationships with supervisors and coworkers who use the IT to perform their day-to-day tasks. Given the important roles that a new IT is likely to play in organizations, avoiding it will make it difficult for an employee to be an active member of the organization. Beaudry and Pinsonneault (2005) noted that employees who avoided an IT had to find alternative ways (e.g., workarounds) to accomplish their tasks. Consequently, it is possible that these employees will feel a lack of attachment to their organizations, supervisors, and coworkers. We noticed that some of our focus group participants who continued to use Microsoft Excel expressed frustrations regarding how their work environment and interpersonal relationships had changed because of the new IT (e.g., they were not able to get help from coworkers who stopped using Microsoft Excel for similar tasks). They mentioned that they were not particularly happy about these changes. Overall, we suggest that employees engaging in avoidance are likely to experience a decline in job satisfaction.

Нypothesis 14 (H14). Avoidance will positively influence a decrease in (a) job performance and (b) job satisfaction following an IT implementation.

\section{Method}

We conducted two field studies to test our model. Study 1 was conducted in the context of an ERP system implementation in an electronic components manufacturer. Study 2 was conducted in the context of a product lifecycle management (PLM) system implementation in a Fortune 500 consumer goods manufacturer. Both studies spanned approximately six months, with data collection taking place at four points in time. During the time of our data collection, use of these two systems was not mandatory in either organization but was strongly encouraged, because the organizations, following the advice of the consultants and vendors, wanted to ensure the continuity of operations in the event that the systems failed to support certain operations and/or processes immediately after implementation.

\subsection{Research Sites and Participants}

Participants in study 1 were users of two modules of SAP ERP systems, namely, human capital management (HCM) and financials. The organization was a medium-sized enterprise, with a little over 3,000 employees. A total of 837 employees who used these modules on a daily basis as a part of their jobs were invited by email to participate in this study, with the $T_{0}$ survey administered before the training (see Figure 2). We also asked the supervisors $(N=121)$ of these employees to complete performance evaluations for these employees. These supervisors were provided a list of their subordinates who were users of the SAP modules. Although employees were aware of the fact that supervisor-rated job performance data would be collected for this study, they were informed that their responses would be confidential because supervisors would have no information about who among their subordinates actually participated in the study and how they (the subordinates) responded. Similarly, the employees had no access to the supervisorrated performance data. The data files were securely stored by the authors, and participating organizations did not have access to any identifying information. A Microsoft Excel-based tool was developed to perform the employee-supervisor matching based on the unique survey IDs generated by the survey system and employee email addresses. Employee email addresses were removed from the data file immediately after the matching was performed and validated. We received 97 usable responses from supervisors at $T_{0}(80 \%$ response rate). A total of 56 supervisors (58\% response rate) provided employee performance ratings at $T_{3}$ for the 211 employees who provided usable responses at $T_{3}$ (overall $46 \%$ response rate). These response rates are consistent with prior studies that collected supervisor ratings (e.g., Yuan and Woodman 2010).

Given that the study duration was six months with four points of measurement, it was practically impossible to have all invited employees participate in all waves of data collection; i.e., in each wave, we invited all participants from the previous round. A total of $582(69 \%)$ employees participated in the survey

Figure 2 Data Collection Procedure

\begin{tabular}{|c|c|c|c|c|c|c|c|}
\hline $\begin{array}{c}\text { Activity } \\
\text { before } \\
\text { measures }\end{array}$ & Measures & $\begin{array}{c}\text { Activity } \\
\text { between } \\
\text { measures }\end{array}$ & Measures & $\begin{array}{c}\text { Activity } \\
\text { between } \\
\text { measures }\end{array}$ & Measures & $\begin{array}{c}\text { Activity } \\
\text { between } \\
\text { measures }\end{array}$ & Measures \\
\hline & $\begin{array}{c}\text { Job } \\
\text { outcomes }\end{array}$ & Training & $\begin{array}{c}\text { Implementation } \\
\text { characteristics }\end{array}$ & $\begin{array}{c}\text { System use } \\
\text { for 2 months }\end{array}$ & $\begin{array}{c}\text { Cognitive } \\
\text { appraisals }\end{array}$ & $\begin{array}{c}\text { System use } \\
\text { for 3 months }\end{array}$ & $\begin{array}{c}\text { Technology adaptation } \\
\text { and job outcomes }\end{array}$ \\
\hline
\end{tabular}

\begin{tabular}{|c|c|c|c|}
\hline$T_{0}$ & $T_{1}$ & $T_{2}$ & $T_{3}$ \\
Preimplementation & 1 month after $T_{0}$ & 2 months after $T_{1}$ & 3 months after $T_{2}$ \\
\hline
\end{tabular}


at $T_{0}$. We received 436 usable responses at $T_{1}(75 \%)$, 298 usable responses at $T_{2}(68 \%)$, and 211 usable responses at $T_{3}(71 \%)$. Of the 211 participants, 137 were men $(65 \%)$ and the average age was 44.1 , with a standard deviation of 12.91. The final sample included employees from multiple business units (e.g., human resources, accounting, supply chain, customer services) who were primarily accountants, account managers responsible for supply chain activities, and HR employees. To test for response biases and attrition effects on our results, we examined demographic differences (age, gender, and organizational tenure) among employees who participated (a) only at $T_{0}$, (b) only at $T_{1}$, (c) only at $T_{2}$, (d) only at $T_{3}$, and (e) at $T_{0}, T_{1}, T_{2}$, and $T_{3}(N=211)$. We did not find any significant differences in any of these comparisons, suggesting that there was no significant response bias in our sample.

The context of study 2 was a multimodule PLM system implementation in a large manufacturing company that had over 60,000 employees in locations in the United States and around the world. The project manager provided us a list of 386 employees who were going to participate in the training. We followed the same procedure in this study as we did in study 1 . We invited 386 employees to participate in the $T_{0}$ survey (before the training) and received 302 usable responses at $T_{0}(78 \%), 254$ usable responses at $T_{1}(84 \%), 221$ usable responses at $T_{2}(87 \%)$, and 181 usable responses at $T_{3}(82 \%)$. Of these 181 participants, 82 were men $(45 \%)$, and the average age was 39.26 , with a standard deviation of 9.67. We followed the same procedure as study 1 to test for response biases and attrition effects and did not find any significant response bias in our sample.

\subsection{Data Collection Procedure}

The data collection procedure was similar in both studies (see Figure 2). We received a schedule of module deployment, training programs, and a list of participating employees' email addresses from the IT implementation project managers in both organizations. In study 1 , a five-day intensive training program was conducted by the consulting firm that implemented the two SAP modules. In study 2, a three-day on-site training program was conducted by the vendor that implemented the PLM system. We collected preimplementation performance ratings from supervisors before the on-site training.

We requested business unit managers to send an initial email to participating employees about the survey before each wave of data collection. Following this email, we sent a customized invitation email to each employee with a unique uniform resource locator (URL), created by the survey software. When an employee clicked on the URL to start the survey, the survey software was able to detect the particular employee and matched him or her with the unique ID for that employee. This unique ID and employee email address were used to match the responses from the subsequent surveys $\left(T_{1}, T_{2}\right.$, and $\left.T_{3}\right)$ and to match the supervisor ratings of employees' job performance. Supervisors also used the same survey software to provide performance ratings. Two reminders were sent over the two-week period for which the survey was open.

\subsection{Measures}

In both studies, previously validated measures were used wherever possible (see Table 1). We adapted the measures for cognitive appraisals from prior social psychology research. Perceived opportunity was assessed using four items adapted from DrachZahavy and Erez (2002) and Major et al. (1998). Perceived threat and perceived controllability were assessed using four items, each adapted from Major et al. (1998). Following prior research (Drach-Zahavy and Erez 2002, Major et al. 1998), coping theory, and guidelines from the literature (Petter et al. 2007), we operationalized perceived opportunity and perceived threat using reflective indicators. Although items of these two constructs capture different aspects of opportunity and threat, these items "share a common theme" - the sense of opportunity or threat (Petter et al. 2007, p. 635). It has been suggested that if items of a construct have a common core that theoretically represents the construct, these items can be modeled as reflective (Petter et al. 2007). ${ }^{1}$ We assessed job performance using four items from Janssen and Van Yperen (2004). These items indicated whether an employee was able to fulfill his or her job responsibilities effectively. Job satisfaction was measured using an extensively used three-item measure from Camman et al. (1983). One of the adaptation behaviors, namely avoidance, was measured using four items from Klein et al. (2001). We developed measures for the other three adaptation behaviors-exploration-to-innovate, exploration-to-revert, and exploitation-following the procedures outlined by DeVellis (2003). We conducted a pilot study using a sample of executive MBA students $(N=94)$ to assess the reliability and construct validity of these new scales. We used the data from the pilot study to conduct item-level exploratory and confirmatory factor analyses. Based on these analyses, we included four items per construct, which is considered to be sufficient for validity and reliability (see Venkatesh et al. 2003), in our final surveys to keep the

\footnotetext{
${ }^{1}$ Despite these reasons, it could be argued that perceived opportunity and perceived threat should be modeled using formative constructs. We did this as well, and the findings are discussed in the results section.
} 


\section{Table $1 \quad$ List of Items}

\begin{tabular}{|c|c|c|}
\hline Constructs & Items & Source \\
\hline $\begin{array}{l}\text { User participation } \\
\text { (UPART) }\end{array}$ & $\begin{array}{l}1 \text { I played an important role in the development and/or implementation of the system. } \\
2 \text { I felt my opinion was adequately considered during the process of development and/or } \\
\text { implementation of the system. } \\
3 \text { I participated in the development and/or implementation of the system. } \\
4 \text { I was an important part of the development and/or implementation of the system. }\end{array}$ & Barki and Hartwick (1994) \\
\hline $\begin{array}{l}\text { User involvement } \\
\text { (UINV) }\end{array}$ & $\begin{array}{l}1 \text { I consider the new system to be important to me. } \\
2 \text { I consider the new system to be of great concern to me. } \\
3 \text { I consider the new system to be relevant to me. } \\
4 \text { I consider the new system to be significant. }\end{array}$ & Barki and Hartwick (1994) \\
\hline $\begin{array}{l}\text { Management } \\
\text { support (MGMT) }\end{array}$ & $\begin{array}{l}1 \text { The management supports the implementation of this system. } \\
2 \text { The management understands the potential benefits of this system. } \\
3 \text { The management encourages the use of this system. } \\
4 \text { The management provides necessary help/resources for this system. }\end{array}$ & Sharma and Yetton (2007) \\
\hline $\begin{array}{l}\text { Training } \\
\text { effectiveness } \\
\text { (TRNG) }\end{array}$ & $\begin{array}{l}1 \text { I got a great deal of information on the system during formal training. } \\
2 \text { The training on the system seemed of very high quality. } \\
3 \text { Training materials were valuable for me to learn this system. } \\
4 \text { The amount of time I spent in formal training on the system was adequate. }\end{array}$ & $\begin{array}{l}\text { Klein et al. (2001), Aiman-Smith } \\
\text { and Green (2002) }\end{array}$ \\
\hline $\begin{array}{l}\text { Perceived } \\
\text { opportunity } \\
\text { (POPP) }\end{array}$ & $\begin{array}{l}1 \text { I am confident that the system will have positive consequences for me. } \\
2 \text { I feel that the system will open new avenues for success in my job. } \\
3 \text { The system will provide opportunities to improve my job performance. } \\
4 \text { The system will provide opportunities to gain recognition and praise. }\end{array}$ & $\begin{array}{l}\text { Drach-Zahavy and Erez (2002), } \\
\text { Major et al. (1998) }\end{array}$ \\
\hline $\begin{array}{l}\text { Perceived threat } \\
\text { (PTHRT) }\end{array}$ & $\begin{array}{l}1 \text { I am scared that the system will have harmful (or bad) consequences for me. } \\
2 \text { I am worried that the system may worsen my job performance. } \\
3 \text { I feel that the system might actually degrade my status in the organization. } \\
4 \text { I feel stressed about having to use the system to accomplish my job. }\end{array}$ & Major et al. (1998) \\
\hline $\begin{array}{l}\text { Perceived } \\
\text { controllability } \\
\text { (PCNTR) }\end{array}$ & $\begin{array}{l}1 \text { I personally have what it takes to deal with the situations caused by the system. } \\
2 \text { I have the resources I need to successfully use the system. } \\
3 \text { I have the knowledge necessary to use the system. } \\
4 \text { I am confident that I will be able to use the system without any problems. }\end{array}$ & Major et al. (1998) \\
\hline $\begin{array}{l}\text { Exploration-to- } \\
\text { innovate } \\
\text { (EXPLRI) }\end{array}$ & $\begin{array}{l}1 \text { Explore the system for potential new application to my work context. } \\
2 \text { Explore the system to find new ways of accomplishing my tasks. } \\
3 \text { Discover new ways of using the system to accomplish my tasks. } \\
4 \text { Experiment with the system to find features to accomplish tasks in novel ways. }\end{array}$ & New items \\
\hline $\begin{array}{l}\text { Exploitation } \\
\text { (EXPLT) }\end{array}$ & $\begin{array}{l}1 \text { Routinely use the same features of the system that I learned from training or others to perform } \\
\text { my tasks. } \\
2 \text { Use a set of common system features that were suggested during the training or by others. } \\
3 \text { Routinely use a set of system features that were recommended during the training and by others } \\
\text { to do my day-to-day activities. } \\
4 \text { Use the features that I learned from training or from others to do my job. }\end{array}$ & New items \\
\hline $\begin{array}{l}\text { Exploration-to- } \\
\text { revert } \\
\text { (EXPLRV) }\end{array}$ & $\begin{array}{l}1 \text { Search for those system features that would support my old ways of doing things. } \\
2 \text { Try to modify system features to perform my tasks in my old ways when this system was not } \\
\text { here. } \\
3 \text { Search for those features that would help me accomplish tasks the way I used to perform them } \\
\text { before the system was implemented. } \\
4 \text { Change some system features so that it fits my old work habits. }\end{array}$ & New items \\
\hline Avoidance (AVOID) & $\begin{array}{l}1 \text { Try to avoid the system as much as I can. } \\
2 \text { Find ways to complete most of my daily activities without using the system. } \\
3 \text { Try to perform most of my tasks without using the system. } \\
4 \text { Stay away from using the system as much as I can. }\end{array}$ & Klein et al. (2001) \\
\hline $\begin{array}{l}\text { Job performance } \\
\text { (JPERF) }\end{array}$ & $\begin{array}{l}1 \text { This worker always completes the duties specified in his/her job description. } \\
2 \text { This worker meets all the formal performance requirements of the job. } \\
3 \text { This worker fulfills all responsibilities required by his/her job. } \\
4 \text { This worker successfully performs essential duties. }\end{array}$ & $\begin{array}{l}\text { Janssen and Van Yperen } \\
\text { (2004) }\end{array}$ \\
\hline $\begin{array}{l}\text { Job satisfaction } \\
\quad(\text { JSAT) }\end{array}$ & $\begin{array}{l}1 \text { All things considered, I am satisfied with my job. } \\
2 \text { In general, I don't like my job. (Reverse coded) } \\
3 \text { In general, I like working here. }\end{array}$ & Camman et al. (1983) \\
\hline
\end{tabular}

Note. Seven-point Likert scales ("strongly disagree" to "strongly agree") were used for all constructs except EXPLRI, EXPLRV, EXPLT, and AVOID, for which the seven-point scale was "hardly ever do this" to "almost always do this." 
length of the survey manageable while maintaining content validity. The items we included had the highest factor loadings in the pilot study and represented the content domain well (see Venkatesh et al. 2003).

\section{Results}

We used partial least squares (PLS), a componentbased structural equation modeling (SEM) technique, to conduct the data analysis. PLS has been widely used to test for complex structural models, such as ours, that have direct, mediated, and interactions effects. ${ }^{2}$ We used SmartPLS 2.0 (Ringle et al. 2005) to test various models. We employed a bootstrapping method (1,000 times) that used randomly selected subsamples to test significance levels of the various PLS models.

\subsection{Measurement Validation}

We employed both procedural and statistical remedies to mitigate the threat of common method biases following the guidelines from prior research and found no significant threats (Podsakoff et al. 2003). Table 2 presents the correlation matrices and descriptive statistics for studies 1 and 2. To assess construct validity and reliability, we followed the guidelines of Fornell and Larcker (1981). Internal consistency reliabilities (ICRs) were greater than 0.70 for all constructs at all time periods in both studies. The square roots of the shared variance between the constructs and their measures were higher than the correlations across constructs, thus supporting convergent and discriminant validity (Fornell and Larcker 1981). Factor loadings were greater than 0.70 for all constructs at all time periods, with all cross loadings being lower than the loadings, thus supporting convergent and discriminant validity (Setia et al. 2013). ${ }^{3}$ A confirmatory factor analysis (CFA) using a covariance-based approach yielded strong support for the proposed measurement model in both studies.

\footnotetext{
${ }^{2}$ For a covariance-based SEM analysis, we needed to estimate 143 distinct parameters without the interaction terms for our structural model. Therefore, our sample sizes of 211 and 181 in studies 1 and 2, respectively, were inadequate for such an analysis. Given the large number of parameters being estimated, we ran a structural model in AMOS 17, a covariance-based SEM tool, using a singleindicator approach (e.g., Yuan and Woodman 2010). The results from both analyses (PLS and least squares SEM) were qualitatively the same, indicating the robustness of our findings.

${ }^{3}$ We did not find any qualitative differences in results when we modeled perceived opportunity and perceived threat as formative constructs: no paths gained or lost statistical significance and no significant paths changed in sign. This is likely a result of very similar weights of different items when we modeled them as formative indicators, and the resulting latent scores were not very different from what they were when they were modeled using reflective indicators. The factor analysis and high interitem correlations $(r>$ 0.80 in both studies) also confirm that these items covary and have characteristics of a reflective construct.
}

\subsection{Structural Model Results}

Given that our model includes both moderators and mediators, we conducted a three-stage moderated mediation analysis following the guidelines of Edwards and Lambert (2007). The goal of this analysis is to demonstrate that the direct and moderating effects in our model are fully and/or partially mediated by their respective mediators. We compared the $R^{2}$ between the structural models for each dependent variable to assess the incremental variance explained by the mediators and the moderators (Aiken and West 1991). We mean-centered the variables at the indicator level prior to creating the product terms of the moderators and independent variables (Aiken and West 1991). All variance inflation factors (VIFs) were less than three, indicating that multicollinearity was not a problem.

4.2.1. Predicting Technology Adaptation. We posited that cognitive appraisals will have both direct and moderating effects on technology adaptation. Results, shown in Table 3, indicate that the hypothesized direct effects of cognitive appraisals (i.e., perceived opportunity, perceived threat, and perceived controllability) on adaptation behaviors (i.e., exploration-to-innovate, exploitation, explorationto-revert, and avoidance) were significant in both studies except for the effect of perceived controllability on exploitation and exploration-to-revert, thus supporting $\mathrm{H} 1(\mathrm{a}), \mathrm{H} 1(\mathrm{~b}), \mathrm{H} 2(\mathrm{a}), \mathrm{H} 3(\mathrm{a}), \mathrm{H} 4(\mathrm{a})$, and H4(b). We also found support for all the hypothesized moderating effects except for the effect on explorationto-revert, thus supporting $\mathrm{H} 1(\mathrm{c}), \mathrm{H} 2(\mathrm{c})$, and H4(c). As shown in Figure 3, for employees with high perceived controllability, perceived opportunity had a stronger positive effect on exploration-to-innovate. For employees with low perceived controllability, perceived opportunity had a stronger positive effect on exploitation and perceived threat had a stronger positive effect on avoidance (see Figure 3). Overall, our model explained $28 \%$ and $23 \%$ of the variance in exploration-to-innovate, $24 \%$ and $26 \%$ of the variance in exploitation, $28 \%$ and $21 \%$ of the variance in exploration-to-revert, and $32 \%$ and $44 \%$ of the variance in avoidance in studies 1 and 2, respectively (see Table 3).

4.2.2. Predicting Cognitive Appraisals. We predicted that both experiential and psychological engagements would have a direct effect on cognitive appraisals, and psychological engagements would also have a moderating effect. As shown in Table 4, experiential engagements (i.e., user participation and training effectiveness) had a significant influence on cognitive appraisals (i.e., perceived opportunity, perceived threat, and perceived controllability), thus supporting H5(a), H5(b), H5(c), H6(a), H6(b), and H6(c). 
几

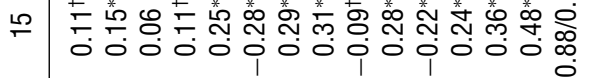

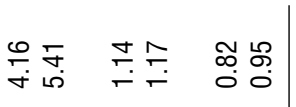

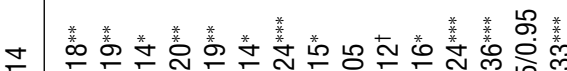

(2)

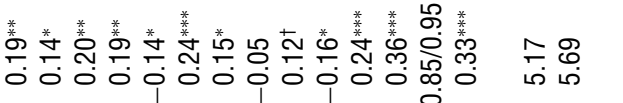

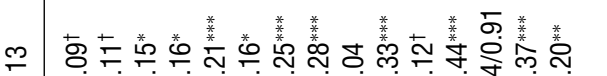

ம்

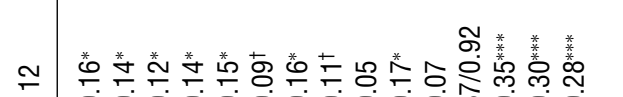

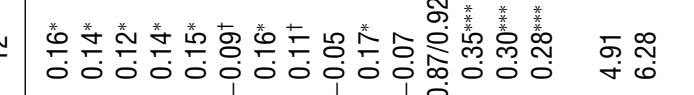

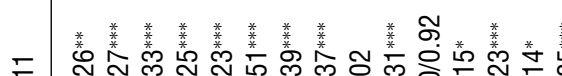

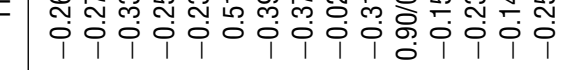

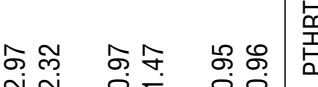

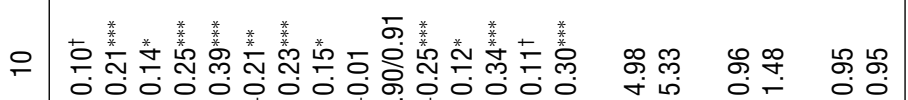

๑ ช ช

ঙ্ল

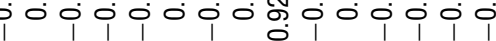

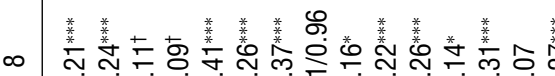

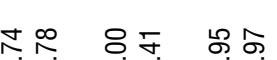
0.000 0.

mi

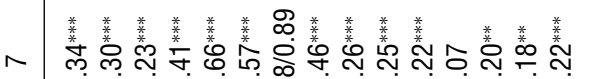

잉 000000000000000

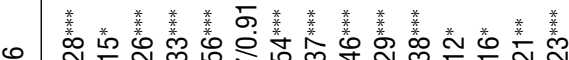
1

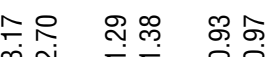

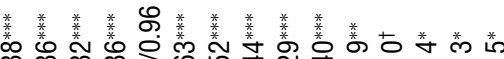

เ

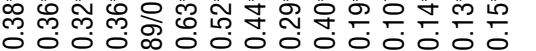

$\infty \circ$

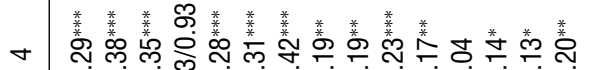

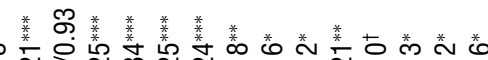

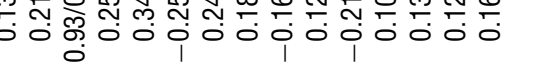

皮

色守守 \&

$\sim$

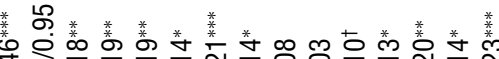

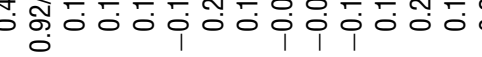

무유요용 웅

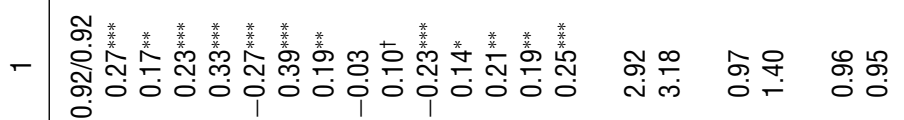

ता 0 ○.

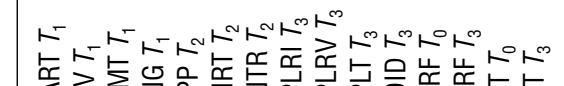

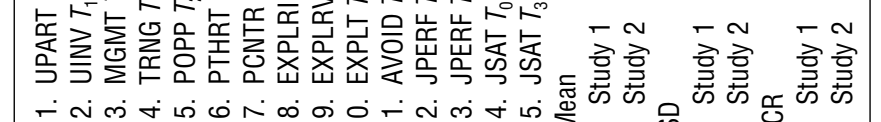

率

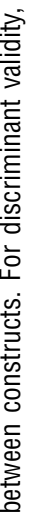


Figure 3 Moderating Effects of Cognitive Appraisals on Technology Adaptation

(a) Moderating effect on exploration-to-innovate

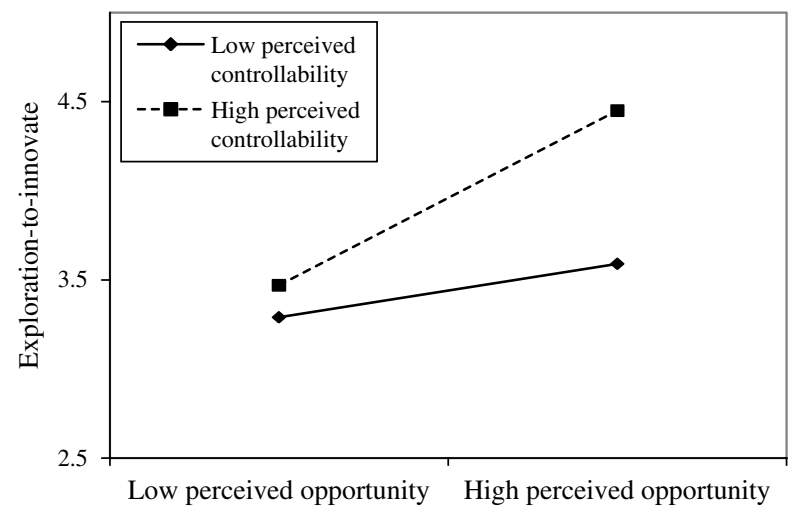

(b) Moderating effect on exploitation

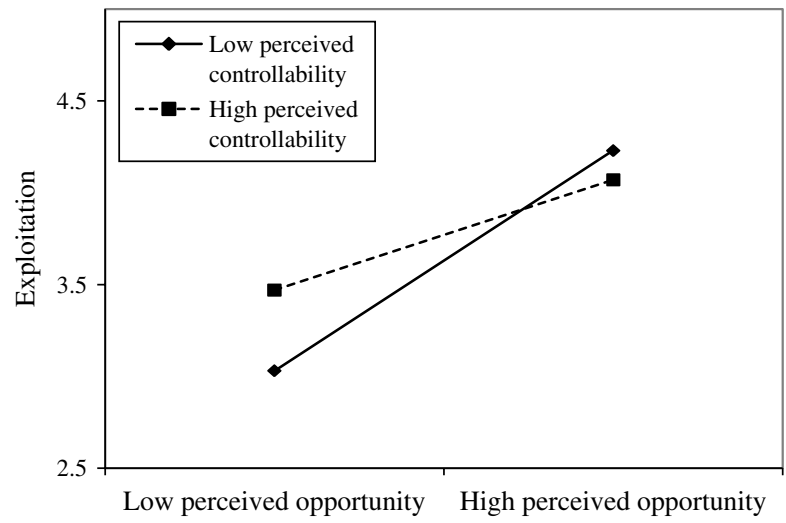

(c) Moderating effect on avoidance

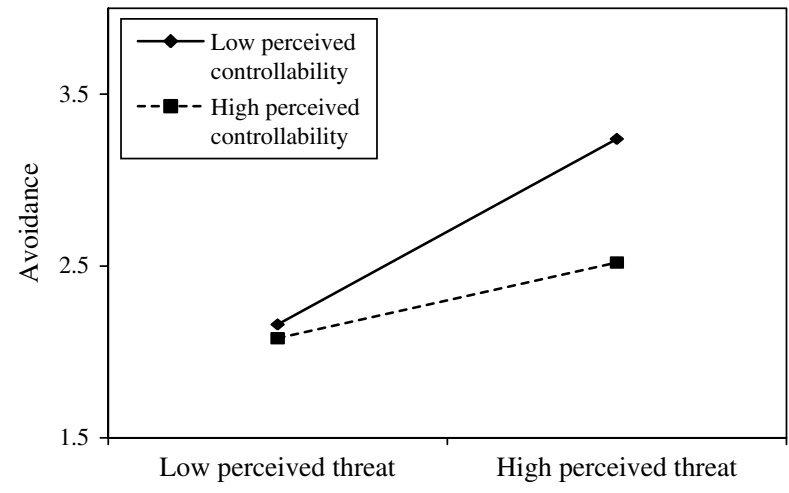

Psychological engagements (i.e., user involvement and management support) had a significant positive effect on perceived opportunity, thus supporting H7(a) and H8(a). Management support had a negative influence on perceived threat, thus supporting H8(b). Further, psychological engagements had a significant moderating effect on perceived opportunity and perceived threat. In particular, the results indicate that the effects of user participation and training effectiveness on perceived opportunity were stronger in the presence of low and high user involvement, respectively, thus supporting H9(a) and H9(c) (see Figure 4).
Further, the effects of user participation and training effectiveness on perceived threat were stronger in the presence of high management support, thus supporting $\mathrm{H} 10(\mathrm{~b})$ and $\mathrm{H} 10(\mathrm{~d})$ (see Figure 4). Psychological engagements had no moderating effects on perceived controllability. Overall, our model explained 33\% and $32 \%$ of the variance in perceived opportunity, $27 \%$ and $25 \%$ of the variance in perceived threat, and $28 \%$ and $26 \%$ of the variance in perceived controllability in studies 1 and 2, respectively.

4.2.3. Predicting Job Outcomes. We suggested that two adaptation behaviors, exploration-toinnovate and exploitation, would have a positive effect and that the other two adaptation behaviors, exploration-to-revert and avoidance, would have a negative effect on job outcomes. Following prior research (Moon et al. 2004, Parker et al. 1997), we created change scores for job outcomes by subtracting the $T_{0}$ scores from the $T_{3}$ scores. $T_{0}$ measures were included as control variables to partial out their effects (Parker et al. 1997). Exploration-to-innovate and exploitation had significant positive effects on changes in job outcomes, thus supporting H11(a), H11(b), H12(a), and H12(b) (see Table 5). Explorationto-revert had a significant negative effect on changes in job outcomes, thus supporting H13(a) and H13(b). Avoidance had no significant effect on changes in job outcomes. Given that job outcomes actually decreased from $T_{0}$ to $T_{3}$, the sign of the coefficients indicates an opposite relationship between technology adaptation behaviors and job outcomes. For example, the positive coefficient of the effect of exploration-to-innovate on change in job performance indicates that employees with a high degree of exploration-to-innovate are likely to experience less of a decrease in job performance between $T_{0}$ and $T_{3}$. Our model explained between $28 \%$ and $32 \%$ of the variance in changes in job outcomes.

\section{Discussion}

We developed and tested a holistic nomological network of technology adaptation that links IT implementation to employee job outcomes. We found strong support for our model. Our findings have important implications for theory and practice.

\subsection{Theoretical Contributions}

This research contributes to the literature in several ways. First, we offer a holistic view of technology adaptation, an important postimplementation phenomenon, by developing a nomological network that incorporates cognitive appraisals and implementation characteristics as antecedents, and job performance and job satisfaction as outcomes. We build on Beaudry and Pinsonneault (2005) who conceptualized 
Table 3 Predicting Technology Adaptations

\begin{tabular}{|c|c|c|c|c|c|c|c|c|c|c|c|c|}
\hline \multirow[b]{4}{*}{ Predictors } & \multicolumn{6}{|c|}{ Exploration-to-innovate } & \multicolumn{6}{|c|}{ Exploitation } \\
\hline & \multicolumn{3}{|c|}{ Study 1} & \multicolumn{3}{|c|}{ Study 2} & \multicolumn{3}{|c|}{ Study 1} & \multicolumn{3}{|c|}{ Study 2} \\
\hline & \multicolumn{3}{|c|}{ Models } & \multicolumn{3}{|c|}{ Models } & \multicolumn{3}{|c|}{ Models } & \multicolumn{3}{|c|}{ Models } \\
\hline & 1 & 2 & 3 & 1 & 2 & 3 & 1 & 2 & 3 & 1 & 2 & 3 \\
\hline \multicolumn{13}{|c|}{ Implementation characteristics } \\
\hline \multicolumn{13}{|c|}{ Direct effects } \\
\hline UPART & $0.12^{*}$ & -0.03 & -0.02 & $0.13^{*}$ & -0.02 & -0.01 & 0.07 & 0.04 & 0.03 & 0.03 & 0.09 & 0.07 \\
\hline TRNG & 0.08 & -0.03 & -0.01 & 0.01 & -0.03 & -0.01 & $0.18^{* *}$ & $0.12^{*}$ & 0.10 & $0.17^{* *}$ & $0.13^{*}$ & 0.10 \\
\hline UINV & 0.04 & 0.03 & 0.01 & $0.14^{*}$ & 0.08 & 0.04 & 0.10 & 0.09 & 0.08 & $0.14^{*}$ & 0.08 & 0.08 \\
\hline MGMT & $0.11^{*}$ & 0.01 & 0.01 & 0.03 & -0.01 & -0.01 & 0.07 & -0.03 & 0.05 & 0.05 & -0.02 & 0.03 \\
\hline \multicolumn{13}{|l|}{ Moderating effects } \\
\hline UPART × UINV & 0.08 & 0.01 & 0.01 & 0.04 & -0.01 & -0.01 & -0.03 & -0.01 & 0.03 & 0.03 & -0.04 & 0.02 \\
\hline TRNG × UINV & 0.06 & 0.04 & 0.03 & -0.02 & -0.02 & -0.01 & 0.04 & -0.02 & -0.06 & -0.04 & 0.06 & -0.03 \\
\hline UPART × MGMT & 0.04 & 0.00 & 0.00 & 0.09 & 0.03 & 0.02 & 0.08 & 0.07 & 0.05 & 0.09 & 0.08 & 0.04 \\
\hline TRNG $\times$ MGMT & 0.07 & 0.03 & 0.01 & 0.01 & 0.01 & 0.01 & 0.01 & 0.04 & 0.06 & 0.04 & 0.03 & 0.00 \\
\hline \\
\hline & \multicolumn{12}{|c|}{ Direct effects } \\
\hline POPP & & $0.31^{* * *}$ & $0.29^{* * *}$ & & $0.27^{* * *}$ & $0.25^{* * *}$ & & $0.34^{* * *}$ & $0.31^{* * *}$ & & $0.43^{* * *}$ & $0.42^{* * *}$ \\
\hline PTHRT & & -0.04 & -0.03 & & -0.02 & -0.02 & & -0.03 & -0.01 & & -0.02 & -0.01 \\
\hline PCNTR & & $0.26^{* * *}$ & $0.22^{* *}$ & & $0.21^{* *}$ & $0.20^{* *}$ & & 0.08 & 0.04 & & 0.09 & 0.05 \\
\hline \multicolumn{13}{|l|}{ Moderating effects } \\
\hline POPP $\times$ PCNTR & & & $0.12^{*}$ & & & 0.07 & & & $-0.14^{*}$ & & & $-0.15^{*}$ \\
\hline PTHRT × PCON & & & -0.01 & & & -0.06 & & & 0.03 & & & 0.07 \\
\hline$R^{2}$ & 0.10 & 0.23 & 0.28 & 0.13 & 0.22 & 0.23 & 0.08 & 0.19 & 0.24 & 0.11 & 0.20 & 0.26 \\
\hline Adjusted $R^{2}$ & 0.08 & 0.22 & 0.26 & 0.11 & 0.21 & 0.21 & 0.08 & 0.17 & 0.22 & 0.09 & 0.18 & 0.24 \\
\hline$\Delta R^{2}$ & & $0.13^{* * *}$ & $0.05^{* *}$ & & $0.09^{* * *}$ & 0.01 & & $0.11^{* * *}$ & $0.05^{* *}$ & & $0.09^{* * *}$ & $0.06^{* *}$ \\
\hline & & & Exploratior & n-to-rever & & & & & Avoi & dance & & \\
\hline & & Study 1 & & & Study 2 & & & Study 1 & & & Study 2 & \\
\hline & & Models & & & Models & & & Models & & & Models & \\
\hline & 1 & 2 & 3 & 1 & 2 & 3 & 1 & 2 & 3 & 1 & 2 & 3 \\
\hline $\begin{array}{l}\text { Implementation charac } \\
\text { Direct effects }\end{array}$ & & & & & & & & & & & & \\
\hline UPART & -0.03 & -0.09 & -0.05 & -0.02 & -0.06 & -0.04 & $-0.17^{* *}$ & $-0.11^{*}$ & -0.10 & $-0.15^{*}$ & $-0.11^{*}$ & -0.08 \\
\hline TRNG & $-0.16^{*}$ & -0.05 & -0.01 & -0.09 & -0.03 & -0.05 & -0.09 & -0.03 & -0.02 & -0.07 & 0.05 & -0.03 \\
\hline UINV & -0.08 & -0.03 & -0.06 & -0.10 & -0.06 & -0.03 & -0.01 & -0.02 & -0.02 & -0.10 & -0.10 & -0.07 \\
\hline MGMT & $-0.11^{*}$ & -0.05 & -0.03 & $-0.14^{*}$ & $-0.12^{*}$ & -0.09 & $-0.15^{*}$ & $-0.12^{*}$ & -0.09 & $-0.21^{* *}$ & $-0.16^{*}$ & -0.10 \\
\hline Moderating effects & & & & & & & & & & & & \\
\hline UPART $\times$ UINV & -0.05 & 0.02 & -0.01 & 0.03 & 0.05 & -0.02 & 0.05 & 0.04 & 0.05 & 0.09 & 0.08 & 0.06 \\
\hline TRNG $\times$ UINV & 0.07 & 0.04 & -0.06 & 0.04 & -0.02 & 0.03 & 0.03 & -0.02 & 0.03 & 0.01 & -0.04 & 0.02 \\
\hline UPART $\times$ MGMT & 0.08 & -0.01 & 0.04 & -0.02 & 0.03 & 0.01 & 0.08 & 0.05 & 0.02 & 0.10 & 0.05 & -0.03 \\
\hline TRNG × MGMT & 0.03 & 0.02 & -0.03 & 0.03 & 0.01 & 0.00 & -0.04 & -0.01 & -0.03 & 0.06 & 0.09 & 0.07 \\
\hline Cognitive appraisals & & & & & & & & & & & & \\
\hline Direct effects & & & & & & & & & & & & \\
\hline POPP & & -0.01 & -0.01 & & $-0.11^{*}$ & -0.09 & & $-0.11^{*}$ & 0.08 & & $-0.14^{*}$ & -0.10 \\
\hline PTHRT & & $0.34^{* * *}$ & $0.32^{* * *}$ & & $0.33^{* * *}$ & $0.30^{* * *}$ & & $0.37^{* * *}$ & $0.34^{* * *}$ & & $0.40^{* * *}$ & $0.36^{* * *}$ \\
\hline PCNTR & & $-0.23^{* * *}$ & $-0.22^{* *}$ & & $-0.20^{* *}$ & $-0.16^{*}$ & & $-0.17^{* *}$ & $-0.14^{*}$ & & $-0.22^{* *}$ & $-0.19^{* *}$ \\
\hline Moderating effects & & & & & & & & & & & & \\
\hline POPP $\times$ PCNTR & & & 0.07 & & & 0.09 & & & 0.08 & & & 0.03 \\
\hline PTHRT $\times$ PCNTR & & & -0.04 & & & 0.06 & & & $-0.14^{*}$ & & & $-0.15^{*}$ \\
\hline$R^{2}$ & 0.07 & 0.28 & 0.28 & 0.05 & 0.19 & 0.21 & 0.12 & 0.26 & 0.32 & 0.17 & 0.38 & 0.44 \\
\hline Adjusted $R^{2}$ & 0.05 & 0.26 & 0.26 & 0.03 & 0.17 & 0.20 & 0.10 & 0.24 & 0.30 & 0.15 & 0.36 & 0.42 \\
\hline$\Delta R^{2}$ & & $0.21^{* * *}$ & 0.00 & & $0.14^{* * *}$ & 0.02 & & $0.14^{* * *}$ & $0.06^{* *}$ & & $0.21^{* * *}$ & $0.06^{* *}$ \\
\hline
\end{tabular}

Notes. UPART: user participation; UINV: user involvement; MGMT: management support; TRNG: training effectiveness; POPP: perceived opportunity; PTHRT: perceived threat; PCNTR: perceived controllability. $N=211$ (study 1), $N=181$ (study 2).

${ }^{*} p<0.05 ;{ }^{* *} p<0.01 ; * * * 0.001$. 
Table 4 Predicting Cognitive Appraisals

\begin{tabular}{|c|c|c|c|c|c|c|c|c|c|c|c|c|}
\hline \multirow[b]{3}{*}{ Predictors } & \multicolumn{4}{|c|}{ Perceived opportunity } & \multicolumn{4}{|c|}{ Perceived threat } & \multicolumn{4}{|c|}{ Perceived controllability } \\
\hline & \multicolumn{2}{|c|}{ Study 1} & \multicolumn{2}{|c|}{ Study 2} & \multicolumn{2}{|c|}{ Study 1} & \multicolumn{2}{|c|}{ Study 2} & \multicolumn{2}{|c|}{ Study 1} & \multicolumn{2}{|c|}{ Study 2} \\
\hline & Model 1 & Model 2 & Model 1 & Model 2 & Model 1 & Model 2 & Model 1 & Model 2 & Model 1 & Model 2 & Model 1 & Model 2 \\
\hline \multicolumn{13}{|l|}{ Direct effects } \\
\hline UPART & $0.28^{* * *}$ & $0.25^{* * *}$ & $0.24^{* * *}$ & $0.24^{* * *}$ & $-0.24^{* * *}$ & $-0.22^{* * *}$ & $-0.23^{* * *}$ & $-0.20^{* *}$ & $0.31^{* * *}$ & $0.30^{* * *}$ & $0.25^{* * *}$ & $0.24^{* * *}$ \\
\hline TRNG & $0.16^{* *}$ & $0.15^{* *}$ & $0.17^{* *}$ & $0.14^{*}$ & $-0.23^{* * *}$ & $-0.21^{* * *}$ & $-0.24^{* * *}$ & $-0.23^{* * *}$ & $0.33^{* * *}$ & $0.31^{* * *}$ & $0.34^{* * *}$ & $0.32^{* * *}$ \\
\hline UINV & $0.15^{* *}$ & $0.13^{*}$ & $0.18^{* *}$ & $0.16^{*}$ & -0.03 & -0.01 & -0.08 & -0.06 & 0.07 & 0.04 & 0.10 & 0.09 \\
\hline MGMT & $0.17^{* *}$ & $0.14^{*}$ & $0.21^{* * *}$ & $0.18^{* *}$ & $-0.12^{*}$ & -0.10 & $-0.15^{* *}$ & $-0.11^{*}$ & 0.10 & 0.08 & 0.08 & 0.05 \\
\hline \multicolumn{13}{|l|}{ Moderating effects } \\
\hline UPART $\times$ UINV & & $-0.19^{* *}$ & & $-0.16^{* *}$ & & 0.10 & & 0.05 & & 0.10 & & 0.08 \\
\hline TRNG $\times$ UINV & & $0.18^{* *}$ & & 0.07 & & -0.06 & & 0.03 & & 0.05 & & 0.03 \\
\hline UPART $\times$ MGMT & & -0.07 & & -0.02 & & $-0.17^{* *}$ & & $-0.13^{*}$ & & -0.09 & & -0.04 \\
\hline TRNG $\times$ MGMT & & 0.09 & & 0.05 & & $-0.11^{*}$ & & $-0.14^{*}$ & & 0.08 & & 0.07 \\
\hline$R^{2}$ & 0.24 & 0.33 & 0.27 & 0.32 & 0.18 & 0.27 & 0.17 & 0.25 & 0.27 & 0.28 & 0.25 & 0.26 \\
\hline Adjusted $R^{2}$ & 0.23 & 0.31 & 0.25 & 0.30 & 0.16 & 0.24 & 0.15 & 0.23 & 0.26 & 0.26 & 0.23 & 0.23 \\
\hline$\Delta R^{2}$ & & $0.09^{* * *}$ & & $0.05^{*}$ & & $0.09^{* * *}$ & & $0.08^{* *}$ & & 0.01 & & 0.01 \\
\hline
\end{tabular}

Note. UPART: user participation; UINV: user involvement; MGMT: management support; TRNG: training effectiveness. $N=211$ (study 1 ), $N=181$ (study 2).

${ }^{*} p<0.05 ;{ }^{* *} p<0.01 ;{ }^{* * *} p<0.001$.

cognitive appraisals-i.e., opportunity, threat, and control-and a set of adaptation strategies in the context of IT implementations. We extend their work by conceptualizing and operationalizing four adaptation behaviors and incorporating them into a nomological network that links IT implementation characteristics and employee job outcomes. Consistent with prior research (e.g., Beaudry and Pinsonneault 2005), we suggest that these adaptation behaviors are not mutually exclusive because employees may perform an

\section{Figure 4 Moderating Effects of Experiential Engagements on Primary Appraisals}

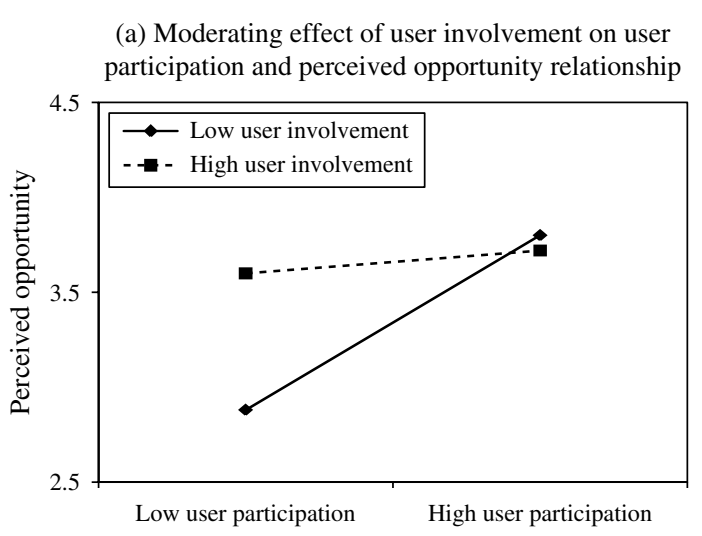

(c) Moderating effect of management support on user participation and perceived threat relationship

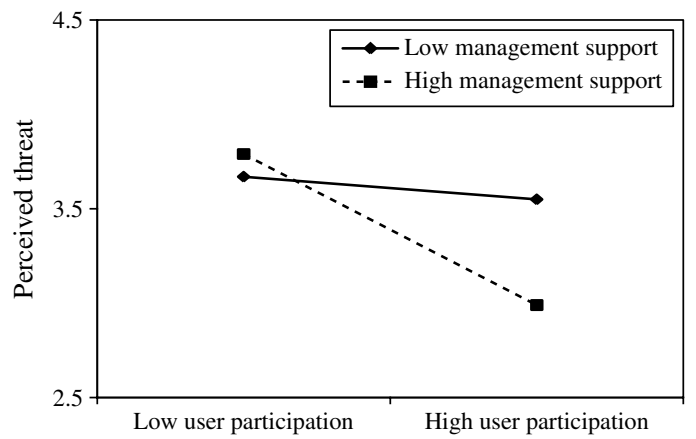

(b) Moderating effect of user involvement on training effectiveness and perceived opportunity relationship

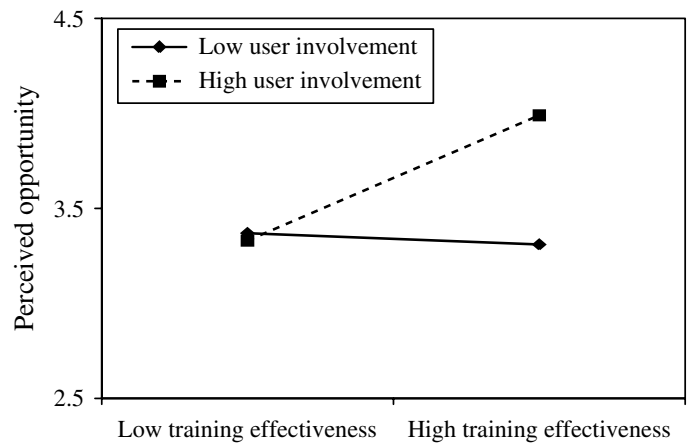

(d) Moderating effect of management support on training effectiveness and perceived threat relationship

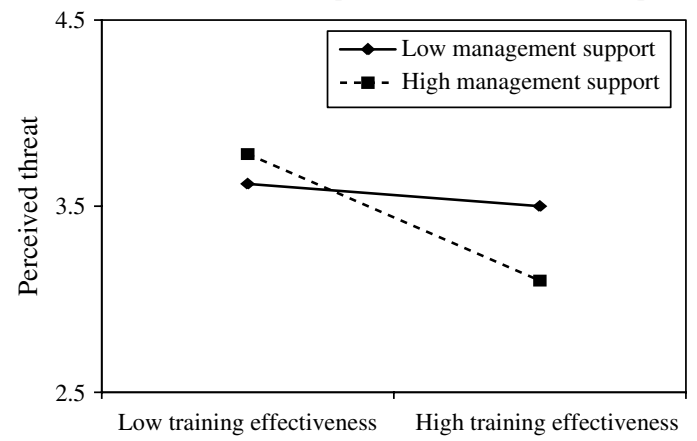




\begin{tabular}{|c|c|c|c|c|c|c|c|c|}
\hline \multirow[b]{3}{*}{ Predictors } & \multicolumn{4}{|c|}{ Change in job performance $\left(T_{3}-T_{0}\right)$} & \multicolumn{4}{|c|}{ Change in job satisfaction $\left(T_{3}-T_{0}\right)$} \\
\hline & \multicolumn{2}{|c|}{ Study 1} & \multicolumn{2}{|c|}{ Study 2} & \multicolumn{2}{|c|}{ Study 1} & \multicolumn{2}{|c|}{ Study 2} \\
\hline & Model 1 & Model 2 & Model 1 & Model 2 & Model 1 & Model 2 & Model 1 & Model 2 \\
\hline \multicolumn{9}{|l|}{ Control variables } \\
\hline $\begin{array}{l}\text { JPERF } T_{0} \\
\text { JSAT } T_{0}\end{array}$ & $-0.22^{* *}$ & $-0.17^{*}$ & $-0.31^{* * *}$ & $-0.29^{* * *}$ & $-0.18^{* *}$ & $-0.19^{* *}$ & $-0.32^{* * *}$ & $-0.33^{* * *}$ \\
\hline \multicolumn{9}{|l|}{ Cognitive appraisals } \\
\hline \multicolumn{9}{|l|}{ Direct effects } \\
\hline POPP & 0.09 & 0.06 & $0.12^{*}$ & 0.07 & 0.09 & 0.08 & $0.11^{\dagger}$ & 0.07 \\
\hline PTHRT & $-0.11^{*}$ & -0.08 & $-0.11^{\dagger}$ & -0.03 & $-0.12^{*}$ & -0.10 & $-0.14^{*}$ & -0.09 \\
\hline PCNTR & 0.07 & 0.07 & $0.13^{*}$ & 0.09 & 0.06 & 0.09 & $0.14^{*}$ & 0.08 \\
\hline \multicolumn{9}{|l|}{ Moderating effects } \\
\hline POPP $\times$ PCNTR & -0.04 & -0.01 & -0.08 & 0.04 & -0.03 & 0.04 & -0.02 & 0.06 \\
\hline PTHRT $\times$ PCNTR & 0.06 & 0.05 & 0.06 & -0.04 & 0.04 & 0.07 & 0.03 & -0.04 \\
\hline \multicolumn{9}{|l|}{ Technology adaptation } \\
\hline EXPLRI & & $0.21^{* *}$ & & $0.23^{* * *}$ & & $0.19^{* *}$ & & $0.21^{* *}$ \\
\hline EXPLT & & $0.15^{*}$ & & $0.20^{* *}$ & & $0.16^{* *}$ & & $0.18^{* *}$ \\
\hline EXPLRV & & $-0.24^{* * *}$ & & $-0.12^{*}$ & & $-0.14^{*}$ & & -0.09 \\
\hline AVOID & & -0.06 & & -0.05 & & -0.08 & & -0.04 \\
\hline$R^{2}$ & 0.14 & 0.32 & 0.16 & 0.29 & 0.15 & 0.28 & 0.19 & 0.32 \\
\hline Adjusted $R^{2}$ & 0.12 & 0.29 & 0.14 & 0.27 & & 0.25 & 0.17 & 0.30 \\
\hline$\Delta R^{2}$ & & $0.18^{* * *}$ & & $0.13^{* * *}$ & & $0.13^{* * *}$ & & $0.11^{* * *}$ \\
\hline
\end{tabular}

Note. JPERF: job performance; JSAT: job satisfaction; POPP: perceived opportunity; PTHRT: perceived threat; PCNTR: perceived controllability; EXPLRI: exploration-to-innovate; EXPLT: exploitation; EXPLRV: exploration-to-revert; AVOID: avoidance. $N=211$ (study 1 ), $N=181$ (study 2).

${ }^{\dagger} p<0.10 ;{ }^{*} p<0.05 ;{ }^{* *} p<0.01 ; * * * 0.001$.

array of adaptation behaviors when faced with a new IT. However, the performance of these behaviors depends on employees' cognitive appraisals of the IT. In fact, we found that although primary appraisalsi.e., perceived opportunity and perceived threathad direct effects on adaptation behaviors, these effects were stronger in the presence (or absence) of secondary appraisals-i.e., perceived controllabilitysuggesting that both types of appraisals operate in tandem with the adaptation process. We also found that employee adaptation behaviors fully mediated the effects of cognitive appraisals on job outcomes, indicating that adaptation behaviors are intervening mechanisms through which employees try to achieve desirable outcomes following an IT implementation that brings radical changes and/or disruptions to their work environment.

Second, our model and findings extend CMUA and prior employee adaptation research by offering antecedents of technology adaptation behaviors and cognitive appraisals (e.g., Barki et al. 2007, Liang and Xue 2009). We incorporated a set of IT implementation characteristics conceptualized as experiential engagements, i.e., user participation and training effectiveness, and psychological engagements, i.e., user involvement and management support,as determinants of cognitive appraisals, thus contributing to the employee adaptation literature in general, which has typically overlooked the role of event characteristics in the process of employee adaptation. These employee engagements during IT implementations represent important coping resources that shape how employees assess an IT implementation and whether they have the necessary resources and abilities to cope with a new IT. The experiential engagements that represent two different aspects of organizational interventions were the key predictors of cognitive appraisals (i.e., perceived opportunity and perceived controllability).

We found that the psychological engagements played important moderating roles. In particular, user participation had the strongest effect on perceived opportunity for those employees who did not feel that the new IT was important or relevant to them (i.e., low user involvement), thus underscoring the importance of user participation in engendering favorable user cognitions. Management support plays a moderating role by offering psychological safety and structural assurance to employees because they may feel that their supervisors will offer emotional and behavioral support following an IT implementation that typically leads to significant performance decline and status change in the workplace (Lapointe and Rivard 2005). Consequently, employees will be motivated to focus on their behavioral efforts (i.e., user participation and training) to overcome perceived negative consequences of an IT. Overall, our model and findings offer key mechanisms (i.e., cognitive appraisals) through which IT implementation characteristics influence technology adaptation. 
Finally, we contribute to the IT implementation literature by examining the impacts of technology adaptation on two important job outcomes: job performance and job satisfaction. Despite repeated calls for examining the impacts of IT implementation (Venkatesh and Bala 2008, Venkatesh et al. 2007), there has been limited research that examines the impacts of IT on job outcomes. Notable exceptions are recent studies that have offered insights on factors that influence job outcomes in the context of IT implementations, such as technology characteristics (e.g., Ayyagari et al. 2011, Morris and Venkatesh 2010), job characteristics (e.g., Bala and Venkatesh 2013, Venkatesh et al. 2010), organizational interventions (e.g., Sykes 2015), and network characteristics (Sykes et al. 2014, Sykes and Venkatesh 2015). Our study extends these studies by offering an important mechanism, technology adaptation, through which IT implementations influence job outcomes. We found that two adaptation behaviors, exploration-to-innovate (e.g., features exploration, extension behaviors) and exploitation (e.g., routinely using a set of known features), were important drivers of job performance and job satisfaction, favorable job outcomes. In contrast, employees engaged in exploration-to-revert did not experience an increase in performance and satisfaction. If employees are engaged in exploration-torevert behaviors, they are likely to be less efficient and their supervisors are likely to lower their (employees) performance ratings because these employees are not using the IT in the intended way and/or prescribed manner. Further, these employees are likely to have a negative affective reaction toward their jobs because they feel an undesirable change in the status quo following the IT implementation. Avoidance did not have a significant effect on job outcomes. We suggest that employees engaged in avoidance behaviors in our studies were likely still able to perform their tasks because learning these new ITs was only quasi-mandatory during the time of our data collection. Therefore, their job performance was not affected by avoidance behaviors. Further, we suggest that employees were not considering the use of the IT as a basis for evaluating their job satisfaction because the use of IT was not mandatory. However, once both organizations fully mandate the use of these ITs, avoidance is likely to have a strong negative effect on job outcomes.

\subsection{Limitations and Future Research}

Our findings should be interpreted in light of their limitations. First, we collected data from two manufacturing organizations. Our findings may not generalize to other types of organizations. However, given that our research sites were significantly different from one another, we felt that the similar results in both studies indicated the robustness and generalizability of our model and findings. Nonetheless, future research should test our model in other contexts. Second, data were collected in the context of two IT implementations, an ERP system and a PLM system. Although these systems are representative of ITs that organizations typically implement, future research should test our model in the context of other types of ITs (e.g., supply chain management, customer relationship management, health care) used by employees with different roles (e.g., boundary-spanning roles). Third, we only collected data six months after the implementation. It is expected that employees' cognitive appraisals and adaptation behaviors will change as they gain more experience with a new IT. A potentially interesting research opportunity will be to conduct a field study in which researchers examine changes in cognitive appraisals and adaptation behaviors over time, predictors of such changes, and impacts of such changes on important outcomes using analytical techniques, such as growth modeling (Bala and Venkatesh 2013).

Several other fruitful research directions can be pursued. An employee may exhibit different adaptation behaviors under different circumstances. Therefore, intraindividual differences in adaptation behaviors can be studied using other methods, such as laboratory experiments and agent-based modeling (e.g., Nan 2011). Individual characteristics (e.g., personality traits, skills) and network characteristics (e.g., an employee's position in different workplace social networks; Sykes and Venkatesh 2015, Sykes et al. 2014) can influence adaptation behaviors. Further, it is possible that IT and work process characteristics (see Sykes et al. 2014) will influence cognitive appraisals and subsequent adaptation behaviors. Finally, there are other important job outcomes(e.g., job engagement, job anxiety, emotional exhaustion, job security, and turnover) that should be studied as outcomes of adaptation. Such work will provide a more comprehensive and integrative understanding of the impacts of an IT implementation on employees' work life (Sykes 2015). Considering the practical challenges of collecting data on different adaptation behaviors and job outcomes, a mixed methods approach could be particularly suitable for conducting such research (Venkatesh et al. 2013).

\subsection{Practical Implications}

This research offers three key implications for practitioners. First, our findings should guide IT managers, project leaders, and vendors in developing effective change management strategies for an IT implementation. Our findings offer insights into employees' underutilization of IT by underscoring the cognitive processes and behavioral responses that employees 
undertake to cope with an IT. Based on these insights, practitioners can develop implementation and change management strategies that are suitable for their organizations (Venkatesh and Bala 2008). For example, although exploration-to-innovate has the strongest positive effects on job outcomes, some practitioners may still favor exploitation as a target adaptation behavior if they feel that it is not possible to increase employees' perception of controllability, a key determinant of exploration-to-innovate, because of the complexity and rigidity of an IT.

Second, with respect to IT implementation characteristics, we found that, in the presence of low user involvement, user participation had a stronger effect on perceived opportunity. An interesting managerial intervention would be to invite those employees to participate in the implementation process who have a low level of user involvement to maximize the impact of user participation on IT implementation success. Further, managers may use simulationbased training to help employees understand the relevance of an IT to their work contexts so that they are not engaged in exploration-to-revert and avoidance behaviors. Finally, our findings have implications for vendors that develop and implement ITs for clients. We urge these organizations to develop implementation strategies that incorporate mechanisms to increase employees' perceptions of opportunity and controllability. One possible mechanism for enabling positive adaptation behaviors is to reduce the misfit of ITs through greater customization during implementation (Bala and Venkatesh 2013).

\section{Conclusions}

We examined how employees cope with an IT that causes disruptions in their work environment. We developed and tested a model that suggested that employees engage in four adaptation behaviors based on how they appraise an IT implementation (i.e., as an opportunity or threat). We suggested and found that four important IT implementation characteristics-user participation, user involvement, management support, and training effectivenessinfluenced employees' appraisals of an IT. We also found that adaptation behaviors significantly influenced changes (pre- versus postimplementation) in job outcomes. Our model and findings contribute to the literature by offering a holistic understanding of technology adaptation behaviors. Our work also provides a basis for future research on the underresearched topic of postadoptive behaviors. Finally, our findings offer insights to IT managers, project leaders, and vendors on how an IT implementation process should be managed to engender favorable adaptation behaviors that in turn will lead to positive employee outcomes.

\section{Acknowledgments}

This paper is based on the first author's doctoral dissertation. The authors thank the following committee: Paul Cronan, Fred Davis, Dan Ganster, and Arun Rai. The authors thank Sandra Slaughter (the department editor), the associate editor, and the two anonymous reviewers for the constructive comments and suggestions that significantly helped improve the paper.

\section{References}

Aiken LS, West SG (1991) Multiple Regression: Testing and Interpreting Interactions (Sage, London).

Aiman-Smith L, Green S (2002) Implementing new manufacturing technology: The related effects of technology characteristics and user learning activities. Acad. Management J. 45(2):421-430.

Ajzen I (1991) The theory of planned behavior. Organ. Behav. Human Decision Processes 50(2):179-211.

Ang S, Slaughter SA (2001) Work outcomes and job design for contract versus permanent information systems professionals on software development teams. MIS Quart. 25(3):321-350.

Ayyagari R, Grover V, Purvis R (2011) Technostress: Technological antecedents and implications. MIS Quart. 35(4):831-858.

Bala H, Venkatesh V (2013) Changes in employees' job characteristics during an enterprise system implementation: A latent growth modeling perspective. MIS Quart. 37(4):1113-1140.

Barki H, Hartwick J (1994) Measuring user participation, user involvement, and user attitude. MIS Quart. 18(1):59-82.

Barki H, Titah R, Boffo C (2007) Information system userelated activity: An expanded behavioral conceptualization of individual-level information system use. Inform. Systems Res. 18(2):173-192.

Beaudry A, Pinsonneault A (2005) Understanding user responses to information technology: A coping model of user adaptation. MIS Quart. 29(3):493-525.

Bendoly E, Cotteleer MJ (2008) Understanding behavioral sources of process variation following enterprise system deployment. J. Oper. Management 26(1):23-44.

Boudreau M-C, Robey D (2005) Enacting integrated information technology: A human agency perspective. Organ. Sci. 16(1):3-18

Burton-Jones A, Straub DW (2006) Reconceptualizing system usage: An approach and empirical test. Inform. Systems Res. 17(3): 228-246.

Camman C, Fichman M, Jenkins JD, Klesh JR (1983) Assessing the attitudes and perceptions of organizational members. Seashore SS, Lawler EE, Mirvis PH, Cammann C, eds. Assessing Organizational Change: A Guide to Methods, Measures, Practices (Wiley, New York), 71-138.

Carver CS, Scheier MF, Weintraub JK (1989) Assessing coping strategies: A theoretically based approach. J. Personality Soc. Psych. 56(2):267-283.

Chan D (2000) Conceptual and empirical gaps in research on individual adaptation at work. Internat. Rev. Indust. Organ. Psych. 15:143-164.

Chattopadhyay P, Glick WH, Huber GP (2001) Organizational actions in response to threats and opportunities. Acad. Management J. 44(5):937-955.

DeSanctis G, Poole MS (1994) Capturing the complexity in advanced technology use: Adaptive structuration theory. Organ. Sci. 5(2):121-147.

DeVellis RF (2003) Scale Development: Theory and Applications (Sage, Thousand Oaks, CA)

Drach-Zahavy A, Erez M (2002) Challenge versus threat effects on the goal-performance relationship. Organ. Behav. Human Decision Processes 88(2):667-682.

Edmondson AC (1999) Psychological safety and learning behavior in work teams. Admin. Sci. Quart. 44(2):350-383. 
Edwards J, Lambert L (2007) Methods for integrating moderation and mediation: A general analytical framework using moderated path analysis. Psych. Methods 12(1):1-22.

Folkman S, Lazarus RS, Gruen RJ, DeLongis A (1986) Appraisal, coping, health status and psychological symptoms. J. Personality Soc. Psych. 50(3):571-579.

Fornell C, Larcker DF (1981) Evaluating structural equation models with unobservable variables and measurement error: Algebra and statistics. J. Marketing Res. 18(3):382-388.

Fugate M, Kinicki AJ, Prussia GE (2008) Employee coping with organizational change: An examination of alternative theoretical perspectives and models. Personnel Psych. 61(1):1-36.

Gartner Inc. (2013) Forecast alert: IT spending, worldwide, 4Q12 update. Report, Gartner, Stamford, CT.

Gupta AK, Smith KG, Shalley CE (2006) The interplay between exploration and exploitation. Acad. Management J. 49(4): 693-706.

Harrison DA, Newman DA, Roth PL (2006) How important are job attitudes? Meta-analytic comparisons for integrative behavioral outcomes and time sequences. Acad. Management J. 49(2):305-326.

Janssen O, Van Yperen NW (2004) Employees' goal orientations, the quality of leader-member exchange, and the outcomes of job performance and job satisfaction. Acad. Management J. 47(3):368-384.

Jasperson J, Carter PE, Zmud RW (2005) A comprehensive conceptualization of post-adoptive behaviors associated with information technology enabled work systems. MIS Quart. 29(3):525-557.

Klein KJ, Conn AB, Sorra JS (2001) Implementing computerized technology: An organizational analysis. J. Appl. Psych. 86(5):811-824.

Lapointe L, Rivard S (2005) A multilevel model of resistance to information technology implementation. MIS Quart. 29(3): 461-491.

Lazarus RS, Folkman S (1984) Stress, Appraisal, and Coping (Springer, New York).

Liang H, Xue Y (2009) Avoidance of information technology threats: A theoretical perspective. MIS Quart. 33(1):71-90.

Major B, Richards MC, Cooper ML, Cozzarelli C, Zubek J (1998) Personal resilience, cognitive appraisals, and coping: An integrative model of adjustment to abortion. J. Personality Soc. Psych. 74(3):735-752.

Mishra AN, Agarwal R (2010) Technological frames, organizational capabilities and post-adoption IT use: An empirical investigation of electronic procurement. Inform. Systems Res. 21(2): 249-270.

Mithas S, Tafti AR, Bardhan IR, Goh JM (2012) Information technology and firm profitability: Mechanisms and empirical evidence. MIS Quart. 36(1):205-224.

Moon H, Hollenbeck JR, Humphrey SE, Ilgen DR, West B, Ellis APJ, Porter COLH (2004) Asymmetrical adaptability: Dynamic team structures as one-way streets. Acad. Management J. 47(5): 681-696.

Morris MG, Venkatesh V (2010) Job characteristics and job satisfaction: Understanding the role of enterprise resource planning system implementation. MIS Quart. 34(1):143-161.

Nan N (2011) Capturing bottom-up information technology use processes: A complex adaptive systems model. MIS Quart. 35(2):505-532.

Parker SK, Chmiel N, Wall TD (1997) Work characteristics and employee well-being within a context of strategic downsizing. J. Occupational Health Psych. 2(4):289-303.

Petter S, Straub D, Rai A (2007) Specifying formative constructs in information systems research. MIS Quart. 31(4):623-656.

Podsakoff PM, Mackenzie SB, Lee J, Podsakoff NP (2003) Common method biases in behavioral research: A critical review of the literature and recommended remedies. J. Appl. Psych. 88(5):879-903.
Purvis RL, Sambamurthy V, Zmud RW (2001) The assimilation of knowledge platforms in organizations: An empirical investigation. Organ. Sci. 12(2):117-135.

Rai A, Tang X (2014) Information technology-enabled business models: A conceptual framework and a coevolution perspective for future research. Inform. Systems Res. 25(1):1-14.

Ringle CM, Wende S, Will A (2005) SmartPLS 2.0 M3 (beta). Hamburg, Germany.

Robey D, Ross JW, Boudreau M-C (2002) Learning to implement enterprise systems: An exploratory study of the dialectics of change. J. Management Inform. Systems 19(1):17-46.

Sabherwal R, Jeyaraj A, Chowa C (2006) Information system success: Individual and organizational determinants. Management Sci. 52(12):1849-1864.

Setia P, Venkatesh V, Joglekar S (2013) Leveraging digital technologies: How information quality leads to localized capabilities and customer service performance. MIS Quart. 37(2):565-590.

Sharma R, Yetton P (2003) The contingent effects of management support and task interdependence on successful information systems implementation. MIS Quart. 27(4):533-556.

Sharma R, Yetton P (2007) The contingent effects of training, technical complexity, and task interdependence on successful information systems implementation. MIS Quart. 31(2):219-238.

Stewart DW, Shamdasani PN, Rook DW (2007) Focus Groups: Theory and Practice (Sage, Thousand Oaks, CA).

Sun $\mathrm{H}$ (2012) Understanding user revisions when using information system features: Adaptive system use and triggers. MIS Quart. 36(2):453-478.

Sykes TA (2015) Support structures and their impacts on employee outcomes: A longitudinal field study of an enterprise system implementation. MIS Quart. 39(2):437-495.

Sykes TA, Venkatesh V (2015) Explaining post-implementation employee system use and friendship, advice and impeding social ties. MIS Quart. Forthcoming.

Sykes TA, Venkatesh V, Johnson JL (2014) Enterprise system implementation and employee job performance: Understanding the role of advice networks. MIS Quart. 38(1):51-72.

Thatcher J, McKnight H, Arsal R, Baker E, Roberts N (2011) The role of trust in post-adoption IT exploration: An empirical examination of knowledge management systems. IEEE Trans. Eng. Management 58(1):56-70.

Venkatesh V, Bala H (2008) Technology acceptance model 3 and a research agenda on interventions. Decision Sci. 39(2):273-315.

Venkatesh V, Bala H, Sykes TA (2010) Impacts of information and communication technology implementations on employees' jobs in India: A multi-method longitudinal field study. Production Oper. Management 19(5):591-613.

Venkatesh V, Brown SA, Bala H (2013) Bridging the qualitativequantitative divide: Guidelines for conducting mixed methods research in information systems. MIS Quart. 37(1):21-54.

Venkatesh V, Davis FD, Morris MG (2007) Dead or alive? The development, trajectory, and future of technology adoption research. J. Assoc. Inform. Systems 8(4):267-286.

Venkatesh V, Brown SA, Maruping LM, Bala H (2008) Predicting different conceptualizations of system use: The competing roles of behavioral intention, facilitating conditions, and behavioral expectation. MIS Quart. 32(3):483-502.

Venkatesh V, Morris MG, Davis GB, Davis FD (2003) User acceptance of information technology: Toward a unified view. MIS Quart. 27(3):425-478.

Venkatesh V, Thong JYL, Chan FKY, Hu PJ-H, Brown SA (2011) Extending the two-stage information systems continuance model: Incorporating UTAUT predictors and the role of context. Inform. Systems J. 21(6):527-555.

Volkoff O, Strong DM, Elmes MB (2007) Technological embeddedness and organizational change. Organ. Sci. 18(5):832-848.

Xue Y, Liang H, Wu L (2011) Punishment, justice, and compliance in mandatory IT settings. Inform. Systems Res. 22(2):400-414.

Yuan F, Woodman RW (2010) Innovative behavior in the workplace: The role of performance and image outcome expectations. Acad. Management J. 53(2):323-342. 